\title{
Share the Fame or Share the Blame? The Reputational Implications of Partnerships*
}

\author{
Luís Almeida Costa ${ }^{\dagger}$ \\ Universidade Nova de Lisboa \\ Faculdade de Economia \\ lacosta@fe.unl.pt
}

\author{
Luís Vasconcelos ${ }^{\ddagger}$ \\ Universidade Nova de Lisboa \\ Faculdade de Economia \\ l-vasconcelos@fe.unl.pt
}

September 2008

\begin{abstract}
We use an adverse selection model to study the dynamics of firms' reputations when firms implement joint projects. We show that in contrast with projects implemented by a single firm, in the case of joint projects a firm's reputation does not necessarily increase following a success and does not necessarily decrease following a failure. We also study how reputation considerations affect firms' decisions to participate in joint projects. We show that a high quality partner may not be preferable to a low quality partner, and that a high reputation partner is not necessarily preferable to a low reputation partner.
\end{abstract}

JEL classification: L14, L15, L24, D82, D85.

Keywords: reputation, partnership, joint project, project performance, Bayesian updating

\footnotetext{
*We would like to thank Adeline Delavande, Fabio Braggion, Heski Bar-Isaac, Iliyan Georgiev, Jon Levin, José Mata, Juan Carrillo, Pedro Santa-Clara, Ran Abramitzky, Steffen Hoernig and seminar participants at the London School of Economics, Tilburg University, Maastricht University, Universidade Nova de Lisboa, the 2007 International Industrial Organization Conference in Savannah, and the 2007 North American Summer Meetings of the Econometric Society in Duke for helpful comments and suggestions. Financial support of the Fundação para a Ciência e Tecnologia under grant POCI/EGE/58934/2004 and of Nova Forum is gratefully acknowledged.

†Universidade Nova de Lisboa, Faculdade de Economia, Campus de Campolide, 1099-032 Lisboa, Portugal. Tel. (+351)213801600. E-mail: lacosta@fe.unl.pt

${ }^{\ddagger}$ Universidade Nova de Lisboa, Faculdade de Economia, Campus de Campolide, 1099-032 Lisboa, Portugal. Tel. (+351)213801600. E-mail: l-vasconcelos@fe.unl.pt.
} 


\section{Introduction}

Firms often engage in joint projects, i.e., projects that involve the contributions of two or more parties. In the case of a joint project, firms are only partially responsible for the project and others may not be able to precisely evaluate each party's contribution to the performance of the project. Consider, for example, the dispute between Ford and Firestone, following the deadly accidents involving Ford Explorers equipped with Firestone ATX tires in the summer of 2000. Was it merely a case of poor tires, as claimed by Ford, or was the design of the Explorer partly responsible for the accidents, as Firestone asserted? The strong controversy that surrounded this dispute and firms' attempts to pass the blame to their partner illustrate how difficult it is to assign responsibility for performance in joint projects. This difficulty makes the reputational dynamics in the case of joint projects rather intricate. In this paper, we study the reputational implications of situations where two firms implement a joint project, sharing the responsibility for its performance. In particular, we address the following questions: How do firms' reputations evolve following the implementation and performance of a joint project? How do the qualities and reputations of the potential partners affect the decision to participate in joint projects? How do reputation considerations affect the choice between individual and joint implementation of projects, when both alternatives are feasible?

Although most of the insights generated in this article apply to many different settings where reputation is important, for concreteness we focus on the situation where firms produce "experience goods", i.e., goods whose performance consumers can only infer after their purchasing decision. Formally, we consider an adverse selection model where firms face the opportunity to implement a joint project through a partnership. We define a partnership broadly as any situation where two or more parties contribute to the performance of a given project. Thus, our definition of partnership encompasses not only joint-ventures, but also vertical relationships where, for example, a firm outsources the production of an important component of a product to another firm as in the case of Ford and Firestone. In our model, firms' qualities are observable only by firms. Consumers hold beliefs about firms' qualities. These beliefs are updated upon observing firms' decision to form a partnership and the performance of the jointly implemented project. We model a firm's reputation as the expected value of its quality, according to consumers' beliefs. Firms' reputations are crucial because consumers base their purchasing decisions on them. In contrast, firms' true qualities are important because they affect the performance of the projects in which firms participate and, thereby, firms' future reputations. We assume that consumers observe the identity of the firm or firms that implement a project. In our context, this means that firms can associate their reputations (and qualities) to a project if and only if they participate in the project. ${ }^{1}$

\footnotetext{
${ }^{1}$ An implication of this assumption is that the reputation and quality (or other fundamental characteristics) of a firm are nonseparable. In the last section of the paper, we discuss the implications of the nonseparability of a firm's reputation and quality, relating it to the concepts of (non)transferability and (non)tradeability of reputations (see e.g., Tadelis, 1999, 2002).
} 
We identify an important difference between projects that are implemented jointly and projects that are implemented by a single firm. Unlike the case of projects implemented by a single firm, in the case of joint projects a firm's reputation may worsen following a success; conversely, a firm's reputation may improve following a failure. The intuition for these results is the following. Consider a partnership where one of the firms contributes more to the implementation of the joint project than its partner. When updating their beliefs about firms' qualities, consumers will tend to attribute the responsibility for a success or a failure of the joint project mainly to that firm. If partners' qualities are perceived by consumers as being negatively correlated, a success of the joint project may then harm the reputation of the other firm and a failure may enhance it. In our model this negative correlation is endogenously generated by the firms' equilibrium implementation strategy of the joint project.

Most of the analysis in the article focuses on projects that cannot be implemented by a single firm. This corresponds to situations where firms have complementary assets or capabilities. In such cases, firms' choice is between implementing the project through a partnership, or simply not pursuing the project. The dynamics of firms' reputations associated with joint implementation crucially depends on firms' equilibrium implementation decisions, as these decisions may signal information about firms' qualities to the market. We focus on equilibria in which firms form a partnership and develop the joint project if and only if their qualities are high. ${ }^{2}$ In these equilibria, a success of the joint project may affect negatively the reputation of one of the firms. However, the overall impact of a success of the joint project on firms' reputations and future profits is positive. Thus, if we define the best partner as the one for which the increase in total profits associated with a partnership is the largest, a high quality partner is preferable to a low quality partner. Regarding the desired reputation of a partner, we identify a basic trade-off. While a high reputation partner enhances the reputation of the joint project, such a partner tends to absorb most of the credit associated with a success and to be disregarded as responsible for a failure. As a result, the impact on a firm's reputation of having a high reputation partner may be negative. If the firm's future projects are sufficiently important relative to the joint project, this negative reputational effect may lead to lower total profits. This implies that a high reputation partner is not necessarily preferable to a low reputation partner.

In the last part of the article, we relax the assumption that individual implementation of the project is not possible. This allows us to discuss the reputational trade-offs involved in the choice between individual and joint implementation. In such cases, a firm that owns a project faces several implementation options. First, it may stretch its reputation to the new project, implementing it alone. Second, it may combine its reputation with that of another firm, implementing the project through a partnership. Third, it may

\footnotetext{
${ }^{2}$ As we shall see, equilibria in which firms develop the joint project if and only if their qualities are low exist in some cases. This type of equilibrium does not survive when sabotage of the joint project is possible, i.e., when firms may make the joint project fail on purpose. In this paper, we focus on sabotage-free equilibria.
} 
fully associate the reputation (and quality) of another firm to the project, by letting that firm implement the project alone. This may be accomplished by selling the project to that firm. ${ }^{3}$ We find that when a firm is particularly concerned about its future reputation, the optimal implementation strategy is largely determined by the relative position of its quality and initial reputation. Specifically, if the firm's quality is substantially lower than its initial reputation, the firm tends to protect its reputation by selling the project to another firm. On the other hand, if the firm's quality is substantially higher than its initial reputation, the firm tends to implement the project alone in order to prove its quality. Finally, if the firm's quality and initial reputation are close, the firm is more prone to form a partnership. In such cases, the firm is neither very reluctant to participate in new projects, nor very eager to implement them alone.

There is an important difference between the case where only joint implementation is possible and the case where individual implementation is also possible. In the former case, firms' qualities are always substitutes, meaning that the higher the quality of a given firm the lower the required quality of a partner for a partnership to be formed. In the latter case, firms' qualities may either be substitutes or complements, where complements means that the higher the quality of a given firm the higher the required quality of a partner for a partnership to be formed. This difference stems from the fact that, when individual implementation is possible, the higher the quality of a firm the more attractive individual implementation by that firm becomes. The fact that firms' qualities may be complements implies that firms' incentive to form a partnership may decrease when the quality of one of the firms increases. Thus, a high quality partner is not necessarily preferable to a low quality partner. This result contrasts with that obtained for the case where individual implementation is not possible.

Related Literature. There are two approaches in the literature to the modeling of reputations. Following the seminal article of Klein and Leffler (1981), several authors have developed moral hazard models of reputation, i.e., models where firms' actions are not observable, and analyze the conditions under which firms have the incentive to exert costly effort to develop or protect a valuable reputation (e.g., Shapiro, 1983; Tirole, 1996; Holmström, 1999; Hörner, 2002). A complementary research stream, which builds on the important articles of Kreps and Wilson (1982) and Milgrom and Roberts (1982), uses adverse selection models of reputation, i.e., models where there is incomplete information about firms' characteristics and reputation corresponds to others' beliefs about those characteristics (e.g., Wernerfelt, 1988; Tadelis, 1999; Cabral, 2000). Ours in an adverse selection model of reputation.

The existing literature on reputation largely focuses on projects developed by a single entity, overlooking the reputational implications of shared responsibility. There are, however, some exceptions. Jeon (1996) analyzes parties' incentives to exert effort in situations of joint production when they are concerned with

\footnotetext{
${ }^{3}$ Since a firm's reputation and quality are nonseparable, the only way to fully associate another firm's reputation to the project is by letting that firm implement the project alone.
} 
their individual reputations, and compares how different organizational forms perform in solving the parties' moral hazard problem. Bar-Isaac (2007) shows that the concern of a "senior" member about the reputation of a professional partnership (or, more specifically, about the reputation of a "junior" member) may induce him/her to exert effort when only the output of the partnership is observed. ${ }^{4}$ Anderson and Smith (2006) study matching decisions when parties' reputations are important, and show that positive assortative matching (in reputations) is generally not an equilibrium. An important difference between our paper and Anderson and Smith (2006), as well as between our paper and Jeon (1996) and Bar-Isaac (2007), is that we consider a setting where firms have better information about their qualities than the market. Thus, the contribution of our paper to this literature is to study the dynamics of firms' reputations when not only the performance of the joint project, but also firms' decision to implement it reveals information about firms' qualities to the market. In this setting, firms' implementation decisions of joint projects depend on the reputational implications (of both the implementation and the performance) of those projects, and, in turn, these reputational implications depend on firms' implementation decisions. ${ }^{5}$

Our paper is related to the articles by Wernerfelt (1988), Cabral (2000) and Miklós-Thal (2008) on brand stretching and to the article by Tadelis (1999) on reputation as a tradeable asset. Wernerfelt (1988), Cabral (2000) and Miklós-Thal (2008) study a firm's choice between stretching its reputation to a new project through brand stretching and marketing the new project under a new brand. Tadelis (1999) focuses on situations where reputations are embedded in names and, as a result, the market for names corresponds to a market for reputations, and analyzes the incentives to buy a name and associate it with a project. These papers assume that reputation and quality are separable. We focus on situations where reputation and quality are nonseparable and study the intermediate case where a firm partially associates an existing reputation to a new project by implementing it through a partnership. Furthermore, we analyze a firm's choice between stretching its reputation, combining its reputation with that of another firm, and fully associating the reputation (and quality) of another firm to the project.

Our paper is also related to the literature on multidimensional signalling (and multidimensional screening)

\footnotetext{
${ }^{4}$ Morrison and Wilhelm (2004) also study the incentives of partners to mentor juniors in order to protect the reputation of a professional partnership. The authors focus on the aggregate reputation of the partnership, not on the reputation of its members. In their model, there is no role for individual reputations. This precludes them from analyzing the impact of joint projects on individual reputations, which is our concern here. Tirole (1996) does study the joint dynamics of individual and collective reputations when modeling the idea of group reputation as an aggregate of individual reputations. However, Tirole focuses on how individual members' incentives (and actions) affect individual and collective reputations, not on how collective actions (for which individual members are jointly responsible) affect those reputations.

${ }^{5}$ In formalizing a theory of scapegoats, Segendorff (2000) shows that a leader may choose an incompetent co-worker so that he can later protect his reputation in case things go wrong by blaming the co-worker. Segendorff also considers that both the leader and the co-worker have private information about their abilities. However, in contrast with our paper, Segendorff (2000) focuses on the case where the leader can prove to others that the co-worker is incompetent after a negative joint outcome has been observed.
} 
(e.g., Quinzii and Rochet, 1985; Wilson, 1985; Engers, 1987; Rochet and Chone, 1998). We assume that side payments between firms are possible and, as a result, firms maximize their joint profit. Hence, conceptually our problem is similar to that of a monopolist with private information about several characteristics which are unknown to consumers. The main concern in the literature on multidimensional signalling has been the existence and characterization of (fully) separating equilibria. In our model, such equilibria cannot exist because the characteristics about which firms have private information (firms' qualities) are continuous and firms' signal space has two elements - to form a partnership or not to do so.

Plan of the Paper. This paper is organized as follows. In Section 2, we present the model. In Section 3, we analyze the impact of the performance of joint projects on partners' reputations. In Section 4, we analyze firms' incentives to form partnerships and characterize all the reputational implications of those decisions. In this section, we focus on projects that cannot be implemented individually. In Section 5, we analyze the case of projects that can be implemented jointly or individually, and study the main reputational trade-offs involved in the choice between joint and individual implementation. In Section 6, we present concluding remarks.

\section{Basic Model}

Consider an economy with a continuum of firms with measure one and two periods, period one and period two. At the beginning of period one a countable (i.e., measure zero) subset of the set of possible pairs of firms are endowed with a joint project, which they may decide to implement or not. Joint projects can only be implemented in period one and last one period if implemented. To capture the dynamic reputational effects of implementing a joint project, we consider that each firm in the economy is endowed with a basic product that it sells individually in period two. ${ }^{6}$ Let firm A and firm B be a pair of firms that is endowed with a joint project. The implementation of the joint project requires the participation of both firms. ${ }^{7}$ The required contribution of firm A to the partnership is $\alpha_{A} \in(0,1)$, which implies the complementary contribution $\alpha_{B}=1-\alpha_{A}$ of firm B. Firms' decision is whether or not to form a partnership and implement the joint project in period one. We assume that side payments between firms are possible. This implies that the division of surplus between firms is immaterial to the decision to form a partnership and implement the joint project. Firms take the decision that maximizes their joint profit.

For concreteness, suppose that the joint project consists of producing and selling a new product. To push reputation to the fore, assume that both this product and firms' basic products are experience goods. Thus, consumers base their purchasing decisions on their expectations of the performance of the products.

\footnotetext{
${ }^{6}$ We could assume that firms also sell their basic products in period one. However, this would unnecessarily complicate the analysis of the basic model without bringing any additional insight.

${ }^{7}$ This assumption is relaxed in Section 5, where we assume that either of the two firms may implement this project alone.
} 
We assume that each of the products either performs well or not. Consumers value the new (joint) product $V$ if it performs well, and 0 if otherwise. Similarly, consumers value firm $i$ 's basic product $V_{i}$ if it performs well, and 0 if otherwise, for all $i \in\{\mathrm{A}, \mathrm{B}\}$. Throughout, we say that the joint project is a success if the joint product performs well and a failure if it does not. ${ }^{8}$

Technology. Firms are endowed with qualities that affect the performance of their products. More specifically, firm $i$ 's quality, $q_{i} \in[0,1]$, represents the probability that its products perform well. We assume that the quality of the joint product, i.e., the probability that the joint product performs well, is a weighted average of the firms' qualities, where the weights are the firms' participation levels in the joint project. Thus, the quality of the joint product given firms' qualities $q \equiv\left(q_{A}, q_{B}\right)$, which we denote by $q_{J}(q)$, is given by

$$
q_{J}(q)=\alpha_{A} q_{A}+\alpha_{B} q_{B} \cdot{ }^{9}
$$

Information. The following is common knowledge. Firms know their qualities. Specifically, each firm knows its own quality and the quality of the potential partner. Consumers do not know firms' qualities. They hold beliefs about these qualities. Consumers' initial beliefs about firm i's quality, i.e., consumers' beliefs about $q_{i}$ at the beginning of period one, are described by the (correct) prior $G_{i}\left(q_{i}\right)$ (with density $\left.g_{i}\left(q_{i}\right)\right)$, for all $i \in\{\mathrm{A}, \mathrm{B}\}$. Consumers may have different priors about firms $\mathrm{A}$ and $\mathrm{B}$, as the two firms may differ in dimensions (not explicitly modelled here) that are observable by consumers. ${ }^{10}$ We assume that these priors are atomless distributions, that $g_{i}\left(q_{i}\right)>0$ for all $q_{i} \in[0,1]$ and $i \in\{\mathrm{A}, \mathrm{B}\}$, and that consumers initially perceive firms' qualities as independent. The prior joint distribution of firms' qualities is denoted by $G(q)$ (with density $g(q)$ ).

Consumers do not observe whether firms are endowed with a joint project at the beginning of period one. However, they do observe firms' decision to form a partnership and implement a joint project. Thus, consumers only learn about the existence of a joint project in case it is implemented. At the end of period one, consumers observe the performance of the joint project in case firms implemented it. We denote the performance of the joint product by $\varphi \in\{f, s\}$, where $\varphi=s$ if the joint project is a success, and $\varphi=f$ if it is a failure. Joint product performance is public information. Although consumers know the identity of each partner and its required contribution to the partnership, they do not observe which firm is responsible for a success or a failure of the joint project.

\footnotetext{
${ }^{8}$ In this model, a firm's production of a given product can be interpreted either as the situation where the firm produces one unit of the product or many units that perform equally.

${ }^{9}$ Alternatively, we could assume a more general function $q_{J}(q)$. As long as this function is increasing in $q_{A}$ and $q_{B}$, the characterization of the equilibria would not change. It should be noted, however, that to ensure the existence of some of the equilibria analyzed in the paper, continuity of $q_{J}(q)$ in $q$ is required.

${ }^{10}$ Suppose, for example, that firms in the economy are distributed in a two-dimensional space $(q, \theta)$, where $\theta$ is observable by consumers. Then, $G_{i}\left(q_{i}\right)$ corresponds to consumers' (correct) prior about firm $i$ 's quality given $\theta_{i}$, for $i \in\{\mathrm{A}, \mathrm{B}\}$. The observable parameter $\theta$ may correspond, for instance, to the size of the firm, to the industry where it operates, or to whether it is listed in the stock exchange or not.
} 
Consumers update their beliefs about firms' qualities both after observing the implementation of the joint project and after observing its performance. Since consumers do not observe whether firms have a joint project available and the set of firms that have one is of measure zero, consumers' posterior beliefs are equal to their prior beliefs if firms do not implement the joint project. This is consistent with the fact that, in practice, consumers typically do not revise their perception about a firm's quality if they observe that no (unexpected) partnership has been formed. ${ }^{11}$ We denote consumers' beliefs after they observe the formation of a partnership and the implementation of the joint project by $H_{1}(q)$ (with density $h_{1}(q)$ ) and call them interim beliefs. Similarly, we denote consumers' beliefs following the observation of the performance of the joint project by $H_{2}(q \mid \varphi)$ (with density $h_{2}(q \mid \varphi)$ ) and call them ex-post beliefs. Consumers observe the performance of the joint project at the end of period one, before they purchase firms' basic products in period two. ${ }^{12}$

Reputation. We define a firm's reputation as the expected value, from the consumers' perspective, of the firm's quality given the information that consumers possess. In our context, a firm's reputation can be interpreted as the expected probability that the firm's products perform well.

There are three types of reputations that are relevant for decision making. First, the initial reputations, which correspond to firms' reputations at the beginning of period one. The initial reputation of firm $i \in$ $\{\mathrm{A}, \mathrm{B}\}$, denoted by $r_{i}$, is the expected value of its quality according to consumers' initial beliefs $G(q)$. Second, the interim reputations, which correspond to firms' reputations after consumers observe firms' decision to form a partnership and implement the joint project. The interim reputation of firm $i \in\{\mathrm{A}, \mathrm{B}\}$, denoted by $r_{i}^{\prime}$, is the expected value of its quality according to consumers' interim beliefs $H_{1}(q)$. Third, the ex-post reputations, which correspond to firms' reputations at the beginning of period two, after consumers observe the formation of a partnership and the performance of the joint project. The ex-post reputation of firm $i \in\{\mathrm{A}, \mathrm{B}\}$, denoted by $r_{i}^{\prime \prime}(\varphi)$, is the expected value of its quality according to consumers' ex-post beliefs $H_{2}(q \mid \varphi)$.

Expected Profits. For simplicity, we assume that firms' production costs of the joint product and of their period two products are zero. Furthermore, we assume that the market is short on the sellers' side and that consumers bid competitively for all the products. Thus, firms' profits associated with a given product

\footnotetext{
${ }^{11}$ Consider, for example, the recent partnership between Harley Davidson and Porsche to produce the V-Rod motorcycle. Suppose that, after considering the implementation of the project, the two companies had instead decided not to pursue it. If consumers were unaware that Harley Davidson and Porsche were considering such a project, it is unlikely that they would update their beliefs about firms' qualities following firms' decision not to implement it.

${ }^{12}$ The results in the paper hold if the measure of firms that have a joint project available to be implemented in period one is positive but small. This is because the interim and ex-post beliefs are continuous in the probability that firms have a joint project available when that probability is zero. The results about existence and characterization of equilibria in Propositions 1 to 3 of Section 4 remain valid even if the measure of firms that have a joint project available is higher.
} 
correspond to the consumers' willingness to pay for that product. ${ }^{13}$

Consumers' willingness to pay for a product is given by their expected benefit from consumption. Hence, consumers' valuation of the joint product when firms implement it is the expected value of $\left(\alpha_{A} \widetilde{q}_{A}+\alpha_{B} \widetilde{q}_{B}\right) V$ according to consumers' interim beliefs. ${ }^{14}$ By definition of reputation, this is equal to

$$
\left(\alpha_{A} r_{A}^{\prime}+\alpha_{B} r_{B}^{\prime}\right) V
$$

In a similar way, consumers' valuation of the basic product of firm $i \in\{\mathrm{A}, \mathrm{B}\}$ sold in period two is the expected value of $\widetilde{q}_{i} V_{i}$ according to ex-post beliefs if firms implement the joint project and to initial beliefs if firms do not implement the joint project. Thus, in case of implementation and performance $\varphi$ of the joint project, this valuation is

$$
r_{i}^{\prime \prime}(\varphi) V_{i}
$$

In case of no implementation of the joint project this valuation is $r_{i} V_{i}$.

When considering the decision to form a partnership, firms compare their expected joint profit with and without implementation of the joint project. Since, in general, these profits depend on firms' qualities, we denote them by $\Pi_{P}(q)$ and $\Pi_{0}(q)$, respectively. From (2.2) and (2.3) it follows that

$$
\Pi_{P}(q)=\left[\alpha_{A} r_{A}^{\prime}+\alpha_{B} r_{B}^{\prime}\right] V+\sum_{i=A, B} r_{i}^{\prime \prime}(f) V_{i}+q_{J}(q) \times \sum_{i=A, B}\left[r_{i}^{\prime \prime}(s)-r_{i}^{\prime \prime}(f)\right] V_{i} .
$$

The first term in (2.4) corresponds to the direct profits from implementing the joint project. The second and third terms in (2.4) correspond to firms' expected profits associated with selling their basic products in period two. Firms' period two profits depend on their ex-post reputations, which are the reputations associated with a success of the joint project with probability $q_{J}(q)$ and the reputations associated with a failure with the complementary probability. Note that the qualities of firms A and B do not affect the profit associated with the joint project; they affect profits only by affecting the performance of the joint project and, thereby, firms' future reputations.

By deciding not to implement the joint project, firms forego the potential profit associated with it, but insulate their reputations from the performance of the joint project. ${ }^{15}$ Firms' joint profit associated with not implementing the joint project is given by

$$
\Pi_{0}(q)=r_{A} V_{A}+r_{B} V_{B}
$$

Equilibrium. We characterize firms' equilibrium decision of whether to form a partnership and implement the joint project for fixed initial beliefs. We denote firms' strategy by $\sigma(q)$, which represents the

\footnotetext{
${ }^{13}$ As, for example, in Tadelis (1999) and Cabral (2000), this assumption allows us to ignore signalling through prices. This allows us to focus on the decision to form a partnership.

${ }^{14}$ Throughout the paper we use tilde signs to denote random variables.

${ }^{15}$ This closely parallels Cabral (2000), where the reputation of an existing brand remains unchanged if the firm decides not to stretch the brand to a new project.
} 
probability that they form a partnership given their qualities. We assume that firms form a partnership if and only if $\Pi_{P}(q)>\Pi_{0}(q)$. Thus, as a tie-breaking rule we assume that firms do not form a partnership if $\Pi_{P}(q)=\Pi_{0}(q)$. We use Bayesian Equilibrium as the equilibrium concept. In equilibrium, firms' decision of whether to form a partnership and implement the joint project maximizes their joint profit given their future reputations, and firms' future reputations are Bayesian consistent with firms' strategy regarding the decision to form a partnership and implement the joint project.

\section{Joint Project Performance and Reputation}

In this section, we characterize the impact of the performance of the joint project on firms' reputations, taking firms' decision to implement it and consumers' interim beliefs as given. This is only a first step in our analysis. In Section 4, we then consider all the reputational implications of implementing the joint project by endogenizing firms' implementation decision and, therefore, consumers' interim beliefs.

Suppose that at the beginning of period one firms A and B formed a partnership and implemented the joint project. Following the observation of the performance of the project at the end of the period, consumers update their beliefs about firms' qualities. They do so by applying Bayes' rule to interim beliefs $H_{1}(q)$. Thus, consumers' ex-post beliefs satisfy

$$
h_{2}(q \mid \varphi)=\frac{\operatorname{Pr}[\varphi \mid q] h_{1}(q)}{\int \operatorname{Pr}[\varphi \mid \widehat{q}] d H_{1}(\widehat{q})}
$$

for all $\varphi \in\{f, s\}$, where $\operatorname{Pr}[\varphi=s \mid q]=q_{J}(q)$ and $\operatorname{Pr}[\varphi=f \mid q]=1-q_{J}(q)$ represent, respectively, the probability that the joint project succeeds and the probability that it fails. Using (3.1) one can characterize the impact of the performance of the joint project on firms' reputations. Lemma 1 offers a useful characterization of firms' ex-post reputations, relating them to the interim reputations.

Lemma 1 The ex-post reputations of firm $i \in\{A, B\}$ in case of a success $(\varphi=s)$ and of a failure $(\varphi=f)$ of the joint project are such that

$$
\begin{aligned}
r_{i}^{\prime \prime}(s)-r_{i}^{\prime} & =\frac{\alpha_{i} \operatorname{var}\left(\widetilde{q}_{i}\right)+\left(1-\alpha_{i}\right) \operatorname{cov}\left(\widetilde{q}_{A}, \widetilde{q}_{B}\right)}{r_{J}^{\prime}}, \\
r_{i}^{\prime \prime}(f)-r_{i}^{\prime} & =-\frac{\alpha_{i} \operatorname{var}\left(\widetilde{q}_{i}\right)+\left(1-\alpha_{i}\right) \operatorname{cov}\left(\widetilde{q}_{A}, \widetilde{q}_{B}\right)}{1-r_{J}^{\prime}}
\end{aligned}
$$

and

$$
r_{i}^{\prime \prime}(s)-r_{i}^{\prime \prime}(f)=\frac{\alpha_{i} \operatorname{var}\left(\widetilde{q}_{i}\right)+\left(1-\alpha_{i}\right) \operatorname{cov}\left(\widetilde{q}_{A}, \widetilde{q}_{B}\right)}{r_{J}^{\prime}\left(1-r_{J}^{\prime}\right)},
$$

where $r_{J}^{\prime}=\alpha_{A} r_{A}^{\prime}+\alpha_{B} r_{B}^{\prime}$, and $\operatorname{var}\left(\widetilde{q}_{i}\right)$ and $\operatorname{cov}\left(\widetilde{q}_{A}, \widetilde{q}_{B}\right)$ are, respectively, the variance of $\widetilde{q}_{i}$ and the covariance between $\widetilde{q}_{A}$ and $\widetilde{q}_{B}$ according to interim beliefs $H_{1}(q)$. 


\section{Proof. See Appendix A.2.}

Lemma 1 characterizes the updating that takes place on firms' reputations when consumers observe the performance of a joint project. In particular, it emphasizes that the change in a firm's reputation depends on consumers' perceived variance of its quality, as well as on consumers' perceived correlation between its quality and the quality of the partner (captured in (3.2)-(3.4) by the covariance term). Note that even if consumers initially perceive firms' qualities as not correlated, this is not necessarily the case after they observe that a partnership has been formed.

When consumers' interim beliefs are such that the correlation between firms' perceived qualities is nonnegative, (3.2) and (3.3) reveal that firms' reputations necessarily increase with a success of a joint project and decrease with a failure. ${ }^{16}$ Observe, however, that if consumers' interim beliefs are such that firms' qualities are negatively correlated, the numerator in (3.2)-(3.4) may eventually be negative. This raises the possibility that a firm's reputation decreases with a success of a joint project and increases with a failure. One important question is whether such an updating may occur in equilibrium when firms' decisions to form partnerships are taken into account. We next analyze this issue among others.

\section{$4 \quad$ Partnership Formation and Reputation Dynamics}

In this section, we analyze firms' decision to form a partnership and the evolution of firms' reputations following this decision. We take into account both the signalling effect of the decision to form a partnership and the effect of the performance of the joint project on firms' reputations.

In equilibrium, consumers' beliefs about firms' qualities must be consistent with firms' strategy $\sigma(q)$. Thus, in equilibrium, consumers' interim beliefs result from applying Bayes rule to initial beliefs $G(q)$. That is, consumer's interim beliefs must satisfy

$$
h_{1}(q)=\frac{\sigma(q) g(q)}{\int \sigma(\widehat{q}) d G(\widehat{q})} .
$$

Clearly, these beliefs may differ from consumers' initial beliefs. Intuitively, this is because firms' decision to form a partnership may signal information about their qualities to consumers. By affecting interim beliefs,

\footnotetext{
${ }^{16}$ This is the case, for example, when consumers' interim beliefs $H_{1}(q)$ are such that firms' qualities are independent. In this case, $\operatorname{cov}\left(\widetilde{q}_{A}, \widetilde{q}_{B}\right)$ in Lemma 1 is 0 , which implies that $r_{i}^{\prime \prime}(s)>r_{i}^{\prime}, r_{i}^{\prime \prime}(f)<r_{i}^{\prime}$ and, consequently, $r_{i}^{\prime \prime}(s)>r_{i}^{\prime \prime}(f)$ for all $i \in\{$ A,B $\}$. Note that the case where consumers' interim beliefs $H_{1}(q)$ are such that firms' qualities are independent comprises the case where consumers are uncertain about the quality of only one firm. Thus, if consumers are uncertain about the quality of only one firm, a success (resp. failure) of the joint project always has a positive (resp. negative) impact on the reputation of that firm. This is what happens when a firm implements a project alone. This is also what happens, for example, in Bar-Isaac (2007). In Bar-Isaac (2007) only the ability of the junior member in the partnership is uncertain. Thus, the junior member's reputation always increases following a good performance of the partnership.
} 
this signalling effect also affects ex-post beliefs. Indeed, from (4.1) and (3.1) it follows that consumers' ex-post beliefs must satisfy

$$
h_{2}(q \mid \varphi)=\frac{\operatorname{Pr}[\varphi \mid q] \sigma(q) g(q)}{\int \operatorname{Pr}[\varphi \mid \widehat{q}] \sigma(\widehat{q}) d G(\widehat{q})} .
$$

From (4.1) and (4.2) it is immediate that firms' interim and ex-post reputations critically depend on firms' equilibrium strategy $\sigma(q)$. Thus, one cannot study the reputational implications of joint projects without analyzing firms' equilibrium decisions regarding the implementation of such projects.

Equipped with the above characterization of consumers' interim and ex-post beliefs, we now investigate how firms' qualities affect their decision to form a partnership and implement the joint project. When deciding whether to form a partnership and implement the joint project, firms consider two main effects. While the implementation of the joint project allows firms to capture the profits associated with this project, it also affects firms future reputations and thereby their future profits. The first effect is always non-negative. The second effect may be negative or positive.

As it is typically the case in signalling games, there always exists a pooling equilibrium in which firms A and B abstain from implementing the joint project regardless of their qualities, i.e., in which $\sigma(q)=0$ for all $q \in[0,1]^{2}$. This equilibrium exists because the notion of Bayesian equilibrium does not impose any restriction on beliefs associated with zero-probability events. In our case, if we make consumers' beliefs sufficiently unfavorable to firms in the event they implement the joint project, we can support a pooling equilibrium in which firms never implement it. In this equilibrium, firms' reputations remain unchanged but would be very low in the event they decided to implement the joint project. A well-known problem of this type of equilibrium is that it crucially relies on the arbitrary assumption of "sufficiently unfavorable" beliefs off-the-equilibrium path. Because of this arbitrariness and the fact that in our model consumers' beliefs determine firms' reputations, which are the major driver of firms' decisions, we ignore this equilibrium in the remainder of the paper. In fact, this equilibrium is not a universally divine equilibrium. ${ }^{17}$

We now focus on equilibria with implementation of the joint project, i.e., equilibria in which at least some (types of) firms A and B form a partnership and implement the joint project. If the value of the joint project $V$ is sufficiently high relative to the values of firms' future projects $V_{A}$ and $V_{B}$ (and of course firms'

\footnotetext{
${ }^{17}$ To be more precise, this equilibrium does not survive the Universal Divinity criterion (criterion D2) in a discretized version of the model where there is a finite (although possibly arbitrarily large) number of firms' types - i.e., firms' qualities - which includes types 0 and 1 . In each iteration, criterion D2 eliminates a quality vector $\left(q_{A}, q_{B}\right)$ different from $(0,0)$ and $(1,1)$. Intermediate vectors are eliminated, rather than those with the lowest combined quality $\alpha_{A} q_{A}+\alpha_{B} q_{B}$ because, as we shall see below, in general firms' payoffs from implementing the joint project may increase or decrease with qualities depending on consumers' beliefs. When only quality vectors $(0,0)$ and $(1,1)$ remain, firms' payoff necessarily increase with a success of the joint project. Thus, quality vector $(0,0)$ is eliminated and only vector $(1,1)$ remains. This eliminates any equilibrium where no pair of firms form a partnership to implement the joint project. All the other equilibria presented in the paper are universally divine equilibria.
} 
interim reputations are bounded away from 0), firms will have the incentive to form a partnership regardless of their qualities. This is because firms' direct profit associated with the joint project will always offset firms' eventual losses in future projects due to reputational implications of the joint project. To make this claim more precise, let $V^{*}$ denote the value of $V$ that satisfies the following condition,

$$
V\left(\alpha_{A} r_{A}+\alpha_{B} r_{B}\right)=\sum_{i=A, B} \frac{\alpha_{i} \operatorname{var}\left(\widetilde{q}_{i}\right)}{\left(1-\alpha_{A} r_{A}-\alpha_{B} r_{B}\right)} V_{i},
$$

where $\operatorname{var}\left(\widetilde{q}_{i}\right)$ corresponds to the variance of $\widetilde{q}_{i}$ according to consumers' initial beliefs $G(q)$. Then, we can state the following.

Proposition 1 A pooling equilibrium in which firms form a partnership and implement the joint project independently of their qualities exists if and only if $V>V^{*}$.

\section{Proof. See Appendix A.2.}

In this equilibrium, firms' decision to form a partnership and implement the joint project is uninformative about firms' qualities. Since no signalling effect exists, consumers update their beliefs about firms' qualities only after observing whether the joint project was a success or a failure. Furthermore, since consumers' interim beliefs and initial beliefs are identical and consumers' initial beliefs are that qualities are uncorrelated, in this equilibrium a success (resp. failure) of the joint project always increases (resp. decreases) both firms' reputations. Condition $V>V^{*}$ ensures that the joint project is implemented when both firms have the lowest possible quality, i.e., when $q_{i}=0$ for all $i \in\{\mathrm{A}, \mathrm{B}\}$. The left-hand side of condition (4.3) corresponds to firms' profit associated with the joint project. The right-hand side represents firms' future losses (in their basic products) triggered by the ex-post reputation implications of the performance of the joint project, when both firms have the lowest possible quality. Since the probability of success of the joint project increases with firms' qualities and, in this equilibrium, a success of the joint project increases firms' reputations, when $V>V^{*}$ all firms are better off implementing the joint project.

We devote the remainder of this section to the analysis of joint projects with value $V \leq V^{*}$. For $V \leq V^{*}$, firms' direct profit associated with the joint project is no longer sufficient to always compensate firms' eventual losses in future projects due to reputational implications of the joint project. Consequently, no equilibrium where firms form a partnership and implement the joint project regardless of their qualities exists. In such cases, the only equilibria with implementation of the joint project are semiseparating equilibria, i.e., equilibria where some but not all (types of) firms A and B form a partnership. As we will see below, these equilibria emerge because firms with a different combined quality $\alpha_{A} q_{A}+\alpha_{B} q_{B}$ may have a different incentive to form a partnership.

Proposition 2 For $V \leq V^{*}$, (i) a semiseparating equilibrium where firms implement the joint project iff their combined quality is above a threshold quality level (higher quality partners equilibrium) always exists, 
and (ii) under some conditions, a semiseparating equilibrium where firms implement the joint project iff their combined quality is below a threshold quality level (lower quality partners equilibrium) exists.

\section{Proof. See Appendix A.2.}

Proposition 2 identifies two types of equilibria: higher quality partners equilibria and lower quality partners equilibria. Higher quality partners equilibria correspond to situations where the impact of the performance of the joint project on firms' reputations is such that a success leads to a higher future joint profit than does a failure. In this case, firms implement the project whenever they can guarantee a success with a sufficiently high probability. Since the probability of success increases with firms' qualities, for a given quality of one of the firms, firms implement the joint product when the quality of the other firm is sufficiently high. Technically, this equilibrium emerges because firms' expected joint profit from implementing the joint project satisfies the single-crossing property with respect to qualities. In our context, this means that firms' incremental gain from implementing the joint project increases with firms' qualities. An immediate implication is that low quality firms do not have the incentive to imitate high quality firms and implement the joint project.

Bayesian updating by consumers implies only that the reputation of one of the firms in the partnership increases with a success of the joint project and decreases with a failure. In fact, it may happen that the reputation of the other firm decreases with a success of the joint project and increases with a failure. The idea that a firm's reputation may decrease following a success of a project in which it participates and increase following a failure may seem somewhat counter-intuitive. One typically expects that being associated with a successful event is better in terms of reputation than being associated with an event that is perceived as a failure. To understand these results let us go back to our model. For concreteness, consider the case of firm A and assume that its participation level in the partnership is low. In case of a success of the joint project, consumers infer that firm B (the one whose contribution to the project is high) has a high quality. Moreover, following implementation of the joint project, consumers perceive firms' qualities as negatively correlated, as implementation occurs more often when firms' qualities are significantly different (i.e., one is high and the other low) than when they are similar. This negative correlation is endogenously generated by the implementation strategy itself, since by assumption firms' qualities are initially perceived as independent. ${ }^{18}$ If this negative correlation is sufficiently high (in absolute value), consumers infer that firm A has a low quality. In case of a failure of the joint project, a similar reasoning would lead to the opposite conclusion. ${ }^{19}$

\footnotetext{
${ }^{18}$ In Miklós-Thal (2008) in equilibrium brand stretching introduces endogenous positive correlation between the quality of the new product and the quality of the initial product, even if qualities were initially perceived as independent. In contrast, in our model the endogenous quality correlation generated in equilibrium by the decision to form a partnership is negative.

${ }^{19}$ The reputational consequences for Health Maintenance Organizations (HMOs) of the release in 2002 of the movie "John Q" illustrate that, in fact, when there is shared responsibility the reputational dynamics may be rather intricate. The release of the
} 
In a higher quality partners equilibrium, a success of the joint project may have a negative effect on the reputation of one of the firms. However, if this negative effect is present it is always dominated by the positive effect of a success on the other firm's reputation. Hence, a higher combined quality implies a higher expected joint profit. We next present an example of a higher quality partners equilibrium where the reputation of one of the firms (firm A) decreases following a success of the joint project and increases following a failure. Because of its extreme simplicity, we provide here an example with two-type firms.

Example 1 Suppose that $q_{i} \in\{0,1\}$ and that consumers initially believe that $q_{i}=1$ with probability $p_{i}$, for all $i \in\{A, B\}$. In this two-type case, a firm's reputation is the consumers' perceived probability that the firm is of quality 1. Thus, $p_{i}$ is the initial reputation of firm i. Consider now an implementation strategy where firms implement the joint project iff $q \in\{(1,0),(0,1),(1,1)\}$, i.e., they abstain from implementing the joint project only if both have quality 0. Given this strategy, Bayesian updating implies that firm i's interim reputation satisfies $r_{i}^{\prime}=p_{i} /\left(p_{A}+p_{B}-p_{A} p_{B}\right)$, for all $i \in\{A, B\}$. In a similar way, Bayesian updating implies that firm i's ex-post reputations satisfy

$$
r_{i}^{\prime \prime}(f)=\frac{\alpha_{j} p_{i}\left(1-p_{j}\right)}{\alpha_{B} p_{A}\left(1-p_{B}\right)+\alpha_{A}\left(1-p_{A}\right) p_{B}} \quad \text { and } \quad r_{i}^{\prime \prime}(s)=\frac{\alpha_{i} p_{i}\left(1-p_{j}\right)+p_{A} p_{B}}{\alpha_{A} p_{A}\left(1-p_{B}\right)+\alpha_{B}\left(1-p_{A}\right) p_{B}+p_{A} p_{B}},
$$

where $j \in\{A, B\}$ with $j \neq i$, for all $i \in\{A, B\}$.

Let $p_{A}=p_{B}=1 / 2$. From (4.4), it follows that $r_{i}^{\prime \prime}(s)<r_{i}^{\prime \prime}(f)$ if and only if $\alpha_{i}<1 / 3$. Suppose, for concreteness, that $\alpha_{A}=1 / 4$. In this case, firms' interim reputations are identical, $r_{i}^{\prime}=2 / 3$ for $i \in\{A, B\}$, firm $A$ 's ex-post reputations are $r_{A}^{\prime \prime}(f)=3 / 4>5 / 8=r_{A}^{\prime \prime}(s)$, and firm B's ex-post reputations are $r_{B}^{\prime \prime}(f)=1 / 4$ $<7 / 8=r_{B}^{\prime \prime}(s)$. Given these interim and ex-post reputations and the fact that firms' reputations remain unchanged if they do not implement the joint project, it can easily be verified that when, for example, $V=1$, $V_{A}=2$ and $V_{B}=5$, firms are (strictly) better off implementing the joint project precisely if and only if $q \in\{(1,0),(0,1),(1,1)\}$.

Lower quality partners equilibria correspond to situations where a success of the joint project has a negative impact on firms' joint profit. This is the case because the negative effect of a success of the joint project on the reputation of one of the firms exists and dominates the positive effect of a success on the other firm's reputation. Since firms have a higher joint profit when the joint project fails than when it succeeds, movie seemed to entail significant reputational risks for HMOs. The movie depicted a desperate man wielding a gun who took over a hospital when his health plan did not cover his son's heart transplant operation. Instead of criticizing filmmakers for the inaccuracies and unfairness of the movie, the American Association of Health Plans reacted by emphasizing the government's responsibility for not helping uninsured and underinsured customers in an advertisement stating "John Q. It's not just a movie. It's a crisis for 40 million people who can't afford health care." As a result, the responsibility for the "crisis" was largely attributed to the government and HMOs' reputation apparently did not suffer. As Mark Goodin, a consultant to the Association put it: “...we got a lot of media coverage, and more important, we didn't come across as inhumane by trying to defend the indefensible" (Alsop, 2004, p. 26). 
firms with high qualities are more reluctant to implement the joint project than firms with low qualities. As in higher quality partners equilibria, here firms' expected joint profit from implementing the joint project satisfies the single-crossing property with respect to qualities. In this case, however, firms' incremental gain from implementing the joint project decreases with firms' qualities. Lower quality partners equilibria may provide an explanation for the fact that firms may implement joint projects of moderate value even when their qualities are low and there is a good chance that the project fails. ${ }^{20}$

We identified all possible types of equilibria. In our setting, there are only two possible types of semiseparating equilibria, higher quality partners equilibria and lower quality partners equilibria, depending on whether a success of the joint project has a positive or negative impact on firms' future profits. It follows from Propositions 1 and 2 that a higher quality partners equilibrium always exists when an equilibrium in which firms implement the joint project regardless of their qualities does not. Proposition 2 also states that there are situations where a lower quality partners equilibrium exists. Note, however, that a lower quality partners equilibrium in which the reputation of firm $i \in\{\mathrm{A}, \mathrm{B}\}$ decreases following a success of the joint project can exist only if $\alpha_{i}<V_{i} /\left(V_{A}+V_{B}\right)$. Furthermore, a lower quality partners equilibrium can exist only if the value of the joint project $V$ is strictly positive. Indeed, when $V$ is zero only higher quality partners equilibria exist among those equilibria with implementation of the joint project. ${ }^{21}$

In a lower quality partners equilibrium, firms are better off if the joint project fails than if it succeeds. Since partners typically have the possibility to influence the performance of a joint project, the fact that firms are better off if the joint project fails than if it succeeds suggests the possibility of sabotage, i.e., the possibility that partners may make the joint project fail on purpose. ${ }^{22}$ When sabotage is possible, lower quality partners equilibria do not exist. To see why this is the case consider the following. Suppose that a lower quality partners equilibrium exists and sabotage is possible. In such an equilibrium, all firms that implement the joint project will sabotage it. Thus, a failure of the joint project is no longer informative about firms' qualities and firms' joint profit under implementation of the joint project is independent of their qualities. It follows that either all pairs of firms or no pair of firms implement the joint project. This leads to a contradiction, since by definition in a lower quality partners equilibrium no full pooling exists.

In the remainder of this section, we focus on higher quality partners equilibria. When $V<V^{*}$, higher quality partners equilibria are the only equilibria with implementation of the joint project that are sabotagefree; they are also the only universally divine equilibria that are sabotage-free. ${ }^{23}$

\footnotetext{
${ }^{20}$ In the equilibrium identified in Proposition 1, low quality firms also implement the joint project. However, such an equilibrium exists only if the value of the joint project is high enough to offset the negative reputational effect associated with its failure.

${ }^{21}$ For a formal proof of these results see Appendix A.2.

${ }^{22}$ Although sabotage is unlikely to occur in some situations because of ethical or legal reasons (e.g., medical doctors performing a surgery together), in most cases it is certainly a real possibility.

${ }^{23}$ In general, we cannot rule out the possibility that there exists more than one higher quality partners equilibrium. However,
} 
In a higher quality partners equilibrium, firms' qualities are substitutes, in the sense that the marginal rate at which firms' qualities can be exchanged so that their incentives to form a partnership remain constant is negative. This is because firms want to ensure a success of the joint project with a certain probability. Thus, the higher the quality of a given firm, the lower the minimum required quality of the partner. More specifically, the rate at which firms' qualities can be substituted so that the joint project is implemented depends on the required contributions of firms A and B to the partnership. This rate, which is given by $-\alpha_{A} / \alpha_{B}$ (or equivalently by $-\alpha_{A} /\left(1-\alpha_{A}\right)$ ), is increasing (in absolute value) in firm A's contribution $\alpha_{A}$. This implies that the higher $\alpha_{A}$, the higher the increment in firm B's quality required to compensate for a given reduction in firm A's quality for the project to be implemented.

We now characterize how a partnership affects the evolution of firms' reputations in a higher quality partners equilibrium. Although the impact of a success or a failure of the joint project on firms' reputations has already been discussed, for completeness we include this result in Proposition 3. In Proposition 3, we also characterize the impact of the decision to form a partnership on firms' reputations, and the combined impact of the decision to form a partnership and of the performance of the joint project on firms' reputations.

Proposition 3 In any higher quality partners equilibrium (i) firms' reputations (weakly) increase following the decision to implement the joint project, (ii) a firm's reputation may increase or decrease following a success or a failure of the joint project, and (iii) firms' reputations following a success of the joint project are higher than their initial reputations.

\section{Proof. See Appendix A.2.}

The first part of Proposition 3 compares firms' interim and initial reputations. The difference between them is that interim reputations incorporate the signalling effect associated with the decision to implement the joint project. Since in a higher quality partners equilibrium firms implement the joint project if and only if their qualities are relatively high, the decision to implement the joint project signals high quality. ${ }^{24}$ This explains why firms' interim reputations are higher than their initial reputations. Thus, the decision to form a partnership and implement the joint project signals high quality. The second part of the Proposition, which compares a firm's ex-post and interim reputations, highlights an important difference between joint projects and projects implemented by a single firm. While in the case where a firm implements a project alone its reputation always increases following a success and decreases following a failure, in the case where a firm implements a project through a partnership the opposite may happen. The third part of the Proposition relates firms' ex-post and initial reputations. The difference between the two reflects the combined impact of

there are situations where it is unique. This is the case, for example, when $G_{A}$ and $G_{B}$ are uniform distributions and firms' contributions to the partnership are identical (i.e., $\alpha_{A}=\alpha_{B}=1 / 2$ ).

${ }^{24}$ The only possible case of a higher quality partners equilibrium in which firms' reputations do not strictly increase following the decision to form a partnership is that where only firms with qualities $q_{A}=q_{B}=0$ do not form a partnership. 
the signalling effect associated with the decision to form a partnership and of the effect of the performance of the joint project on consumers' beliefs. The Proposition states that when the effect of a success of the joint project on a firm's reputation is negative, this effect is dominated by the positive signalling effect.

We now study how firms' initial reputations affect the impact of a partnership on firms' joint profit and, therefore, the decision to form a partnership. By affecting the reputation with which the joint project is launched, a firm's reputation has an obvious positive impact on firms' joint profit under a partnership. However, a firm's reputation may also have a negative impact on its partner's reputation and, thereby, on joint profit. This is so because the higher the firm's reputation, the more consumers will tend to give this firm the credit in case of a success of the joint project and to disregard its responsibility in case of a failure. Proposition 4 captures this effect by showing that a firm may be more demanding in terms of a partner's quality when the partner's reputation is high than when it is low. For convenience, we focus on the higher quality partners equilibrium in which the set of firms' qualities for which a partnership is formed is the greatest. ${ }^{25}$ In our setting, this corresponds to the higher quality partners equilibrium with the lowest combined quality threshold above which firms form a partnership.

Proposition 4 A higher reputation of one of the firms may increase the lowest combined quality threshold level above which firms implement the joint project in a higher quality partners equilibrium.

\section{Proof. See Appendix A.2.}

An immediate consequence of Proposition 4 is that firms' joint profit under a partnership and, as a result, firms' incentive to form a partnership do not necessarily increase with the reputation of a given partner. A partner's reputation has a positive or negative impact on joint profits depending on the relative strength of the two effects mentioned above. In particular, when the other firm's future projects are sufficiently important relative to the joint project, the second effect is likely to dominate.

The results presented in this section have important implications for partner selection in situations where individual implementation of the joint project is not possible. The existing literature on partner selection largely focuses on firms' need to access complementary assets or on organizational learning as the key determinants of partner selection (e.g., Geringer, 1988; Hitt et al, 2000). In contrast, we take complementarity as given and analyze how the quality and reputation of the potential partners affect the dynamics of reputation formation and, thereby, firms' incentives to form a partnership. We define a partnership broadly as any situation where two or more parties contribute to the performance of a given project. Thus, our results apply, for example, not only to partner selection in joint-ventures, but also to the selection of trading partners such as retailers or suppliers. In our setting, the best partner is the one for which the increase in total profits associated with a partnership is the largest. In a higher quality partners equilibrium, a higher quality

\footnotetext{
${ }^{25}$ We say that a set $S_{1}$ is greater than a set $S_{2}$ if $S_{2} \subseteq S_{1}$.
} 
partner is always preferable to a lower quality partner. This is because a success of the joint project leads to a higher future joint profit than a failure and the probability of success increases with firms' qualities. However, a higher reputation partner is not always preferable to a lower reputation partner, because the impact on a firm's reputation of having a higher reputation partner may be negative.

\section{$5 \quad$ Individual $v s$. Joint Implementation}

In this section, we assume that the joint project may be implemented not only jointly but also by either of the two firms alone. ${ }^{26}$ This allows us to analyze the main reputational trade-offs associated with the choice between joint and individual implementation of a project.

When individual implementation is possible, the best alternative to a partnership may be implementation by a single firm. If this is the case, an increase in the quality of that firm affects not only firms' joint profit under a partnership, but also under the best alternative to a partnership. As shown below, this introduces two main differences relative to the results presented in Section 4. First, in a higher quality partners equilibrium, where a success of the joint project leads to a higher joint profit than a failure, an increase in firms' combined quality may decrease firms' incentive to form a partnership. Second, firms' qualities may be complements, meaning that at the margin a higher quality firm may require a higher quality partner to form a partnership.

In general, a firm that has the opportunity to develop a new project faces different implementation options. First, the firm may stretch its reputation to the new project, by implementing it alone. This may be accomplished by marketing the product resulting from the project under the firm's existing brand, a practice that has been designated as "brand stretching" or "umbrella branding" (e.g., Wernerfelt, 1988; Cabral, 2000). In addition, the firm may combine its reputation with that of another firm, by implementing the project through a partnership. Finally, the firm may associate the reputation (and quality) of another firm to the project, by selling the project to that firm, who would implement it alone. In our setting, a firm's reputation and quality are nonseparable. Hence, the only way to fully associate the reputation of another firm to the new project is by letting that firm implement the project alone.

The decision of how to implement the joint project involves a basic trade-off. Through individual implementation, firms associate the reputation of one of them to the project. However, doing so may create too much "exposure" for that firm, as it is fully responsible for the performance of the project. Thus, even if the reputation of, let us say, firm A is high and can therefore be used to boost consumers' perceptions of the project, individual implementation by firm B and joint implementation have the advantage of allowing firm A to insulate its reputation fully or partially from the performance of the project. ${ }^{27}$

\footnotetext{
${ }^{26}$ In spite of the fact that in this section the period one project may be implemented by either of the two firms alone, for convenience we continue to call it the joint project.

${ }^{27}$ The paper by Lang (2003) on team formation studies a related problem. Specifically, Lang analyzes the incentives of two
} 
Throughout this section, we continue to assume that only a subset of measure zero of the set of possible pairs of firms are endowed with a joint project at the beginning of period one. We also assume that a subset of positive measure of those firms that are not endowed with a joint project are endowed with an individual project that they always implement. Thus, while consumers do not expect firms to form partnerships and implement joint projects in period one, they do expect firms to implement individual projects. Moreover, since firms always implement their individual projects, a firm's reputation does not change following the decision to implement an individual project. ${ }^{28}$ Finally, we assume that consumers are unable to distinguish a firm's individual project from a joint project that is implemented individually by the firm. This assumption, together with the fact that firms are expected to implement individual projects (but not joint projects) with positive probability imply that after observing a firm implementing a project alone consumers always infer that it is an individual project of that firm. This means that, from a reputational point of view, consumers treat joint projects implemented by a single firm as individual projects of that firm, and so do we in this section.

Since we are interested in analyzing firms' decisions to form partnerships, we consider the case of two firms that are endowed with a joint project at the beginning of period one. We denote them by firm A and firm B. For simplicity, we consider throughout this section the case where only firm A is endowed with a basic product in period two. Thus, the performance of the joint project is relevant only to the extent that it may affect firm A's ex-post reputation. As before, we assume that if firms A and B form a partnership to implement the joint project, they do so with exogenous participation levels $\alpha_{A}$ and $\alpha_{B}$. Firms' implementation decision is denoted by $\mu \in\{A, B, P\}$, where $\mu=A$ if firm A implements the project alone, $\mu=B$ if firm $\mathrm{B}$ implements the project alone, and $\mu=P$ if firms form a partnership.

We now study how firms' qualities affect the implementation decision of the joint project. We start by characterizing the best alternative to a partnership. In our setting, if firm B implements the joint project alone, it associates its reputation to the joint project and firm A associates its reputation - which remains unchanged - to its period two product. Thus, firms' joint profit is $r_{B} V+r_{A} V_{A}$. This is greater than the joint profit in the situation where the joint project is not implemented, which is $r_{A} V_{A}$. Thus, the best alternative agents, who are concerned with their reputations, to pool their productions by forming a team, when they could continue to produce separately. As in our case, the decision to work jointly (rather than remain separate) allows agents to mitigate the impact of their own performance on their reputation. While in Lang (2003) forming a partnership is a signal of quality because teaming costs decrease with qualities, we consider that partnership formation is cost neutral. In our case, forming a partnership is a signal of quality because quality affects performance, which in turn affects future reputations.

${ }^{28}$ The assumption that firms always implement individual projects simplifies the analysis, but is not crucial to obtain the results presented in this section. The results would be qualitatively the same if we assumed instead that only higher quality firms implement their individual projects in period one if they are endowed with one. This would imply an increase in reputation following the implementation of an individual project and a decrease in reputation in case the firm did not implement any project in period one. 
to a partnership is either implementation by firm A alone or implementation by firm B alone.

Lemma 2 The best alternative to a partnership is implementation by firm A alone if

$$
q_{A} \geq r_{A}+\frac{r_{A}\left(1-r_{A}\right)}{\operatorname{var}\left(\widetilde{q}_{A}\right) V_{A}}\left(r_{B}-r_{A}\right) V \equiv q_{A}^{*},
$$

where $\operatorname{var}\left(\widetilde{q}_{A}\right)$ is the variance of $\widetilde{q}_{A}$ according to the prior $G_{A}(\cdot)$. Otherwise, the best alternative to a partnership is implementation by firm B alone.

\section{Proof. See Appendix A.2.}

Condition (5.1) highlights the main trade-offs involved in the choice between individual implementation by firm A or by firm B. One the one hand, firms take into account the profits associated with the joint project. If $V$ is high, the reputation with which the project is launched is important. This favors implementation by the firm with the highest reputation. On the other hand, firms take into account the impact of the performance of the joint project on the future reputation of firm A, which affects its period two profit. If firm A has a high quality and implements the joint project, a success occurs with high probability. This implies an improvement in the reputation of firm A. In contrast, if firm A has a low quality and implements the joint project the reverse happens. Hence, a high quality of firm A favors individual implementation by firm A relative to individual implementation by firm B, and vice-versa.

We now study firms' choice between individual implementation of the joint project (firm A or firm B) and joint implementation through a partnership. An implementation strategy of the joint project by firms A and B is a mapping $\sigma(q, \mu)$ that for each quality vector $q$ assigns firms' probability of choosing implementation form $\mu \in\{A, B, P\}$.

As in the case where only joint implementation of the project is possible (Section 4), here there also exists an equilibrium in which firms never form a partnership. Again, this equilibrium exists because the notion of Bayesian equilibrium does not impose any restriction on beliefs associated with zero-probability events. Thus, making consumers' beliefs sufficiently unfavorable to firms in the event they form a partnership, we can support an equilibrium in which firms never implement the joint project jointly.

Proposition 5 states that when individual implementation of the joint project is also possible there exists no equilibrium where firms implement the joint project through a partnership regardless of their qualities.

Proposition 5 Suppose that the joint project can be implemented either through a partnership or individually. Then, a pooling equilibrium in which firms form a partnership independently of their qualities does not exist.

Proof. See Appendix A.2.

The result in Proposition 5 contrasts with that in Proposition 1, where we establish that when only joint implementation is possible and $V$ is sufficiently high, there is an equilibrium in which firms implement the 
joint project regardless of their qualities. When only joint implementation is possible, the only alternative to a partnership is not to implement the project at all. This creates pressure on firms to form a partnership to appropriate the high value generated by the joint project. In contrast, when individual implementation is possible firms can capture the profits associated with the joint project without forming a partnership.

We now analyze semiseparating equilibria. Again, we focus on higher quality partners equilibria, where firms are better off if a joint project that is implemented through a partnership succeeds than if it fails. As in Section 4, lower quality partners equilibria, where firms are better off if a joint project that is implemented through a partnership fails than if it succeeds, do not exist if sabotage is possible.

In contrast with Section 4, here the characterization of equilibria depends on whether the best alternative to a partnership is individual implementation by firm A (i.e., $q_{A}>q_{A}^{*}$ ) or by firm B (i.e., $q_{A}<q_{A}^{*}$ ).

Proposition 6 Suppose that the joint project can be implemented either through a partnership or individually and consider any higher quality partners equilibrium. For $q_{A}<q_{A}^{*}$, firms form a partnership if and only if their combined quality $\alpha_{A} q_{A}+\alpha_{B} q_{B}$ is above a threshold quality level. For $q_{A}>q_{A}^{*}$, such threshold quality levels no longer exist, since firms' incentive to form a partnership may decrease as firms' combined quality increases.

\section{Proof. See Appendix A.2.}

For $q_{A}<q_{A}^{*}$, the characterization of higher quality partners equilibria is similar to that in the case where individual implementation is not possible: firms form a partnership whenever their combined quality is sufficiently high. For $q_{A}>q_{A}^{*}$, firms' decision to form a partnership is no longer characterized by such a cutoff rule in terms of firms' combined qualities.

The intuition is the following. In a higher quality partners equilibrium, the joint profit under a partnership is increasing in firms' combined quality. For $q_{A}<q_{A}^{*}$, the best alternative to a partnership is individual implementation by firm B. As in the case where individual implementation is not possible, the joint profit under the best alternative to a partnership is independent of firms' qualities. Thus, the higher the firms' combined qualities the higher their incentives to form a partnership. For $q_{A}>q_{A}^{*}$, the joint profit under the best alternative to a partnership (individual implementation by firm A) is increasing in firm A's quality. This implies that an increase in firms' combined quality - which may involve, for example, a significant increase in $q_{A}$ and a decrease in $q_{B}$ - no longer implies that firms' incentive to form a partnership increases. Indeed it may decrease.

Proposition 6 implies that, for $q_{A}<q_{A}^{*}$, qualities are always substitutes, in the sense that the marginal rate at which firms' qualities can be exchanged so that their incentive to form a partnership remains constant is negative. More specifically, this rate is $-\alpha_{A} / \alpha_{B}$, which is the rate at which qualities $q_{A}$ and $q_{B}$ can be exchanged to keep firms' combined quality constant. In contrast, for $q_{A}>q_{A}^{*}$, qualities may be complements, 
in the sense that the marginal rate at which firms' qualities can be exchanged so that their incentive to form a partnership remains constant is positive. When $q_{A}>q_{A}^{*}$, an increase in firm A's quality increases the joint profit under the best alternative to a partnership, individual implementation by firm A. Thus, the marginal rate at which firms' qualities can be exchanged so that their incentive to form a partnership remains constant is greater when $q_{A}>q_{A}^{*}$ than when $q_{A}<q_{A}^{*}$. It may even happen that when firm A's quality increases, firm B's quality also has to increase for firms' incentive to form a partnership to remain constant. In Example 2, we present a higher quality partners equilibrium where this is the case.

The fact that in a higher quality partners equilibrium qualities may be complements implies that firms' incentive to form a partnership may decrease when the quality of one of the firms increases. Thus, when both individual and joint implementation of the joint project are possible, a higher quality partner is not necessarily preferable to a lower quality partner. ${ }^{29}$ This contrasts with the results obtained in Section 4 for the case where individual implementation is not possible. In that case, qualities are always substitutes and in a higher quality partners equilibrium a higher quality partner is always preferable to a lower quality partner.

Example 2 Suppose that firms' qualities, as initially perceived by consumers, are uniformly distributed, i.e., $g_{i}\left(q_{i}\right)=1$ for all $q_{i} \in[0,1], i \in\{A, B\}$. Suppose also that $\alpha_{A}=0.95, \alpha_{B}=0.05, V=0$ and $V_{A}=20$. In this case, $q_{A}^{*}=r_{A}=0.5$. The following strategy constitutes a higher quality partners equilibrium: (i) if $q_{A} \leq 0.5$, form a partnership if $0.95 q_{A}+0.05 q_{B}>0.1943$ and let firm B implement the joint project alone if otherwise; and (ii) if $q_{A}>0.5$, form a partnership if $q_{B}-12.4917 q_{A}>-11.860$ and let firm $A$ implement the joint project alone if otherwise. In this equilibrium, the decision to form a partnership is a good signal of firms' qualities - firm A's and firm B's initial reputations are 0.5, whereas their interim reputations in the event a partnership is formed are 0.5811 and 0.5111 , respectively. Further, following the formation of a partnership, firm A's ex-post reputation is 0.4589 if the joint project fails and 0.6706 if it succeeds. Finally, when firms choose individual implementation (either by firm A or by firm B), their initial and interim reputations are identical (and equal to 0.5), and only the ex-post reputation of the firm that implements the project is affected by the project's performance. This reputation is $2 / 3$ if the project performs well, and $1 / 3$ if it does not. The equilibrium implementation strategy of the joint project is represented in Figure 1.

In this example, since the value of the joint project is zero, the implementation decision of the joint project is important only because it affects firm A's future reputation. In the example, qualities are complements

\footnotetext{
${ }^{29}$ Segendorff (2000) obtains a similar result. Segendorff shows that a competent leader may choose an incompetent co-worker for insurance motives: if things go wrong, the leader can then blame the co-worker and keep his/her reputation intact. The underlying mechanisms in Segendorff (2000) and in our paper are different though, since in Segendorff (2000) the leader has the opportunity to reveal the true quality of the co-worker in case the outcome of their joint work is unsatisfactory.
} 


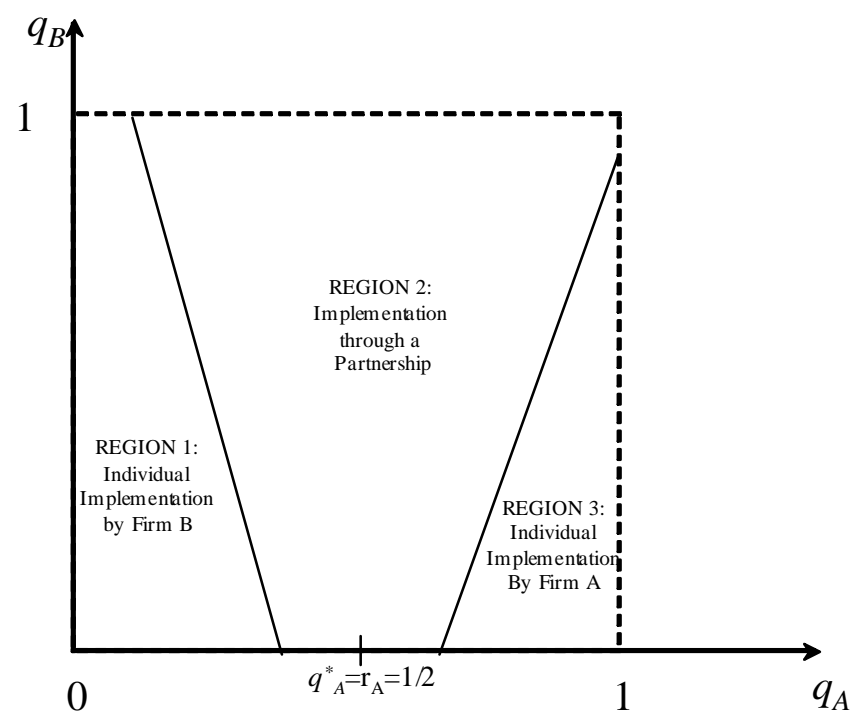

Figure 1: A higher quality partners equilibrium when individual implementation is feasible.

when firm A's quality is high. The intuition is the following. When firm A has a high quality, the best alternative to a partnership is individual implementation by firm A. In addition, the higher the quality of firm A, the more attractive this alternative becomes relative to a partnership. Since in this equilibrium firms' profit from a partnership increases with firm B's quality, the higher the quality of firm A the higher the required quality of firm B for a partnership to be formed.

In Figure 1, we can identify three regions in the space of firms' qualities. Each region corresponds to a different implementation decision of the joint project. In Region 1, firm B implements the joint project alone. In this region, since firm A's quality is relatively low and this firm is the major contributor to the partnership $\left(\alpha_{A}=0.95\right)$, the probability of success of the joint project is low both when firm A implements the project alone and under the partnership. Thus, any of these implementation decisions would jeopardize firm A's future reputation. Implementation by firm B alone insulates firm A's future reputation from the performance of the joint project. In Region 2, forming a partnership is optimal. In this region, firms' combined qualities are sufficiently high to generate a probability of success of the joint project, when implemented through a partnership, that ensures an increase in firm A's future reputation relative to its initial reputation. As a result, the partnership dominates individual implementation by firm B. In addition, in this region firm B's 
quality is sufficiently high (and/or firm A's quality is sufficiently low) for individual implementation by firm A to be dominated by the partnership. Finally, in Region 3 firm A's quality is so high that implementation by firm A alone dominates implementation by firm B alone. Furthermore, since the quality of firm B is relatively low, forming a partnership is also dominated by individual implementation by firm A.

Let us assume that firm A, the firm whose future reputation matters, is the one that initially faces the opportunity to develop the joint project. In this case, we can interpret the regions discussed above in terms of the choice among stretching an existing reputation, fully associating the reputation of another firm to the project, and combining reputations through a partnership, when implementing a new project. Specifically, in Region 1 firm A fully associates the reputation of firm B to the project by selling the project to that firm; in Region 2 firm A combines its reputation with that of firm B through a partnership; and in Region 3 firm A stretches its reputation by implementing the project alone.

Example 2 illustrates important aspects of the management of reputations when firms face the opportunity to develop a new project. Let us again take the perspective of firm A. When firm A's quality is considerably lower than its initial reputation, firm A optimally avoids participating in projects with low value-creation potential per se, unless its partner has a very high quality. This allows firm A to conceal its true quality and to protect its reputation for future use in projects where a good reputation allows it to create high value. In contrast, when firm A's initial reputation is considerably lower than its quality, firm A has the incentive to participate in projects (even of low value) in order to improve its reputation. Finally, when firm A's quality and initial reputation are close, firm $\mathrm{A}$ is more prone to form a partnership, as it is neither very reluctant to participate in projects to hide its true quality nor very eager to implement them alone in order to improve a reputation that is much lower than its true quality. ${ }^{30}$

This discussion emphasizes that a firm's decision to stretch an existing reputation, to combine this reputation with that of another firm, or to fully associate the reputation of another firm to a project crucially depends on the relative position of the firm's own quality and reputation. A higher reputation relative to true quality induces firms to be more conservative and selective in terms of project implementation. A lower reputation relative to true quality induces firms to be more entrepreneurial and implement more projects, in order to raise their public image.

\section{Conclusion}

An important feature of many markets is the existence of information asymmetries about relevant characteristics of firms. In such cases, reputations are critical intangible assets. Furthermore, the increasing

\footnotetext{
${ }^{30}$ These results hold in general, unless the value of the joint project is significantly greater than the value of the firm's future projects. In such cases, the implementation decision is the one that maximizes the profit generated by the joint project, meaning that the firm with the best reputation implements the project individually.
} 
complexity of products and tasks that have to be performed requires an increasing level of specialization, which, in turn, induces firms to increasingly participate in joint projects. In this paper, we study the reputational implications of joint projects and firms' incentives to participate in such projects when reputational considerations are important.

Although we frame our analysis in terms of interaction among firms, most of the insights generated in this paper also apply to situations where individuals, countries or other organizations engage in joint projects. The extent to which our results directly apply to these settings may depend, however, on the assumption of payoff transferability between partners. When payoffs are not transferable, it may be more difficult to convince a party to participate in a partnership if doing so may damage its reputation.

Throughout this paper we assume that the reputation and fundamental characteristics (in our case, the quality) of the reputation holder are nonseparable. This nonseparability limits the transferability or tradeability of reputations. For example, it may not be easy for a firm whose products have performed poorly to buy customers' trust in its products. ${ }^{31}$ Similarly, a well-known scholar cannot sell his or her reputation for producing high-quality research to another less-known scholar. There are certainly situations where reputations are separable and can therefore be traded. When reputations are embedded in names, the market for names corresponds to a market for reputations (e.g., Tadelis, 1999, 2002; Mailath and Samuelson, 2001). ${ }^{32}$ However, a market for names may not exist. Individuals and countries, for instance, cannot buy or sell a name. Even in the case of firms, where markets for names do exist, names may not carry the underlying reputation. In a model where a firm's name is known to all potential customers, Tadelis (1999) obtains that names only carry the underlying reputation to the extent that shifts in ownership are (at least partially) unobservable. In contrast, Hakenes and Peitz (2007) show that, when the name of a firm has a meaning only for the (previous) customers of that firm, names may carry the underlying reputation even if ownership changes are observable. When the reputation and the fundamental characteristics of the reputation holder are separable, parties can insulate their reputations from the consequences of their participation in joint projects. This may be achieved by creating a new brand (or buying an existing one) and associating it with the joint project. Under nonseparability this is not possible.

A final note about efficiency. In our model, total expected surplus is higher when the joint project succeeds than when it fails, except in the obvious case where the joint project has zero value. Therefore, efficiency considerations dictate that when individual implementation is possible, the higher-quality firm

\footnotetext{
${ }^{31}$ As Arrow (1974, p. 23) puts it: "Unfortunately, [trust] is not a commodity which can be bought very easily. [...] Trust and similar values, loyalty and truthtelling, are examples of what the economist would call 'externalities'. They are goods, they are commodities; they have real, practical economic value; [...] But they are not commodities for which trade on the open market is technically possible or even meaningful."

${ }^{32}$ The assumption that firms' reputations and qualities are separable is also implicit in the literature on brand extension (e.g., Wernerfelt, 1988; Cabral, 2000), which associates reputations with brands. Thus, by launching a new product under a totally new brand, a firm associates its quality to that product, but not its existing reputation.
} 
should always implement the joint project alone in order to maximize its probability of success. Our results indicate that in equilibrium this is often not the case. Thus, firms' reputational concerns engender inefficient project implementation decisions. 


\section{Appendices}

\section{A.1. A lower quality partners equilibrium (when only joint implementation is possible)}

Here we present an example of a lower quality partners equilibrium when only joint implementation of the joint project is possible. We consider a case where firms' qualities can take any value in the interval $[0,1]$.

Example 3 Suppose that firms' qualities are initially perceived by consumers as identically distributed. More specifically, suppose that

$$
g_{i}\left(q_{i}\right)=\left\{\begin{array}{c}
0.1 \text { if } q_{i} \leq 0.7 \\
3.1 \text { if } q_{i}>0.7
\end{array},\right.
$$

for all $i \in\{A, B\}$. With these distributions, firms' initial reputations are $r_{i}=0.815$ for all $i \in\{A, B\}$. Suppose also that $\alpha_{A}$ is $0.2, \alpha_{B}=0.8, V_{A}=1, V_{B}=0$ and $V=0.31176$.

For these values, an implementation strategy in which firms implement the joint project iff $q \in\{q \in$ $\left.[0,1]^{2}: 0.2 q_{A}+(0.8) q_{B}<0.7\right\}$ constitutes an equilibrium. In this equilibrium, firms' reputations decrease when consumers observe that firms decided to implement the project jointly. More specifically, firms' interim reputations are $r_{A}^{\prime}=0.68234$ and $r_{B}^{\prime}=0.42742$. After observing that firms formed a partnership and implemented the joint project, consumers perceive firms' qualities as negatively correlated $\left(\operatorname{cov}\left(\widetilde{q}_{A}, \widetilde{q}_{B}\right)=\right.$ -0.04432). This is because consumers know that in equilibrium the higher the quality of a firm, the lower the maximum allowed quality of a partner.

This negative correlation dominates the effect of the variance of $\widetilde{q}_{A}$ in (3.4) (which in this example is $0.08449)$, generating an ex-post reputation of firm $A$ that is higher when the joint project fails than when it succeeds. Specifically, these reputations are $r_{A}^{\prime \prime}(f)=0.71793$ (which is greater than the interim reputation) and $r_{A}^{\prime \prime}(s)=0.64354$, respectively. Thus, in this equilibrium firms' reputations decrease relative to the initial reputations. Firm $A$ is better off in terms of reputation when the joint project fails than when it succeeds. As a result, firms implement the joint project only when they expect the joint project to succeed with a low probability, i.e., only when their qualities are low. We represent graphically the firms' equilibrium implementation strategy in Figure 2.

\section{A.2. Proofs and auxiliary results}

First we show that when individual implementation of the joint project is not possible, a lower quality partners equilibrium can exist only if $V>0$, and a lower quality partners equilibrium in which the reputation of firm $i \in\{\mathrm{A}, \mathrm{B}\}$ decreases following a success of the joint project can exist only if $\alpha_{i}<V_{i} /\left(V_{A}+V_{B}\right)$. 


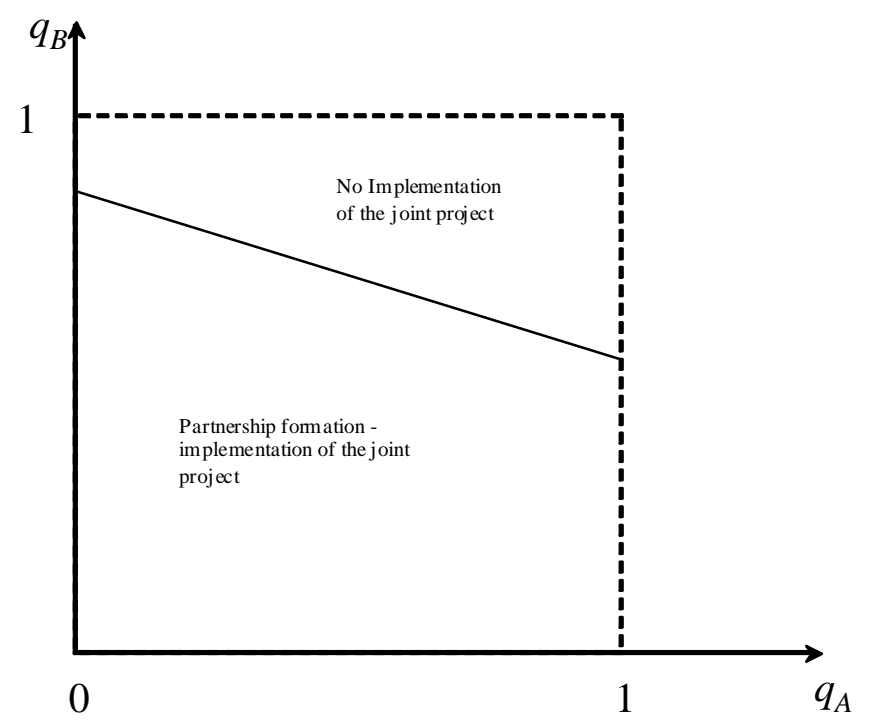

Figure 2: Lower quality partners equilibrium.

Proof. To see that a lower quality partners equilibrium does not exist when $V=0$, consider the case of firms with qualities $q=(0,0)$ in such an equilibrium. Their joint profit is $r_{A}^{\prime \prime}(f) V_{A}+r_{B}^{\prime \prime}(f) V_{B}$ if they implement the joint project, and $r_{A} V_{A}+r_{B} V_{B}$ if they do not. Since $r_{i}^{\prime \prime}(f)<r_{i}$ for all $i \in\{A, B\}$ in any lower quality partners equilibrium (see Lemma 3 below), firms are better off not implementing the joint project. This is a contradiction, since by definition of lower quality partners equilibrium firms with qualities $q=(0,0)$ implement the joint project.

We next prove the second part of the result. Consider a lower quality partners equilibrium. From Lemma 1 , it follows that in such an equilibrium

$$
\alpha_{A}\left[r_{A}^{\prime \prime}(s)-r_{A}^{\prime \prime}(f)\right]+\alpha_{B}\left[r_{B}^{\prime \prime}(s)-r_{B}^{\prime \prime}(f)\right]
$$

is equal to

$$
\frac{\operatorname{var}\left(\alpha_{A} \widetilde{q}_{A}+\alpha_{A} \widetilde{q}_{B}\right)}{r_{J}^{\prime}\left(1-r_{J}^{\prime}\right)}>0
$$

where the $\operatorname{var}\left(\alpha_{A} \widetilde{q}_{A}+\alpha_{A} \widetilde{q}_{B}\right)$ is according to interim beliefs $H_{1}(q)$. Hence, (6.1) is positive. Suppose now that $r_{A}^{\prime \prime}(s)<r_{A}^{\prime \prime}(f)$. (The case where $r_{B}^{\prime \prime}(s)<r_{B}^{\prime \prime}(f)$ is perfectly analogous.) Then, $r_{B}^{\prime \prime}(s)>r_{B}^{\prime \prime}(f)$, since 
(6.1) is positive. By definition of lower quality partners equilibrium, it follows that

$$
\left[r_{A}^{\prime \prime}(s)-r_{A}^{\prime \prime}(f)\right] V_{A}+\left[r_{B}^{\prime \prime}(s)-r_{B}^{\prime \prime}(f)\right] V_{B}<0
$$

From the fact that $(i)(6.1)$ is positive, $(i i) r_{A}^{\prime \prime}(s)<r_{A}^{\prime \prime}(f)$ and $(i i i) r_{B}^{\prime \prime}(s)>r_{B}^{\prime \prime}(f)$, it follows that (6.2) is possible only if $\alpha_{A}<V_{A} /\left(V_{A}+V_{B}\right)$. This completes the proof.

Lemma 3 Suppose only joint implementation of the joint project is possible. Let $\bar{\sigma}(q)$ denote firms' implementation strategy satisfying $\bar{\sigma}(q)=1$ if $q \in\left\{\left(q_{A}, q_{B}\right) \in[0,1]^{2}: \alpha_{A} q_{A}+\alpha_{B} q_{B}>z\right\}$ and $\bar{\sigma}(q)=0$ if otherwise, for $z \in[0,1)$. Similarly, let $\underline{\sigma}(q)$ denote firms' implementation strategy satisfying $\underline{\sigma}(q)=1$ if $q \in\left\{\left(q_{A}, q_{B}\right) \in[0,1]^{2}: \alpha_{A} q_{A}+\alpha_{B} q_{B}<z\right\}$ and $\underline{\sigma}(q)=0$ if otherwise, for $z \in(0,1]$. Given implementation strategy $\bar{\sigma}(q)$, the ex-post reputation of firm $i \in\{A, B\}$ following a success of the joint project is greater than its initial reputation, i.e., $r_{i}^{\prime \prime}(s)>r_{i}$. Further, given implementation strategy $\underline{\sigma}(q)$, the ex-post reputation of firm $i \in\{A, B\}$ following a failure of the joint project is smaller than its initial reputation, i.e., $r_{i}^{\prime \prime}(f)<r_{i}$.

Proof. By definition $r_{i}^{\prime \prime}(\varphi)=\mathbb{E}\left[\widetilde{q}_{i} \mid \varphi\right]$, where $\mathbb{E}\left[\widetilde{q}_{i} \mid \varphi\right]$ corresponds to the expected value of $\widetilde{q}_{i}$ according to the posterior $H_{2}(q \mid \varphi)$, for $\varphi \in\{f, s\}$. Using standard notation, it follows by the law of iterated expectations that $r_{i}^{\prime \prime}(\varphi)=\mathbb{E}_{q_{-i}}\left\{\mathbb{E}\left[\widetilde{q}_{i} \mid \varphi, q_{-i}\right] \mid \varphi\right\}$. Thus, sufficient conditions for the results in the Lemma are that given implementation strategy $\sigma_{1}(q)$ (respectively $\sigma_{2}(q)$ ), $\mathbb{E}\left[\widetilde{q}_{i} \mid s, q_{-i}\right]>r_{i}\left(\right.$ resp. $\mathbb{E}\left[\widetilde{q}_{i} \mid f, q_{-i}\right]<r_{i}$ ) for all $q_{-i}$ such that $h_{2}(q \mid \varphi)>0$ for some $q_{i} . \mathbb{E}\left[\widetilde{q}_{i} \mid \varphi, q_{-i}\right]$ is the expected value of $\widetilde{q}_{i}$ according to the ex-post conditional distribution of $\widetilde{q}_{i}$ given $q_{-i}$. Denoting the density associated with this conditional distribution by $h_{2}\left(q_{i} \mid \varphi, q_{-i}\right)$, by the law of conditional probabilities we have that

$$
h_{2}\left(q_{i} \mid \varphi, q_{-i}\right)=\frac{h_{2}(q \mid \varphi)}{h_{2,-i}\left(q_{-i} \mid \varphi\right)}
$$

where $h_{2,-i}\left(q_{-i} \mid \varphi\right)=\int h_{2}(q \mid \varphi) d q_{i}$ denotes the ex-post marginal distribution of $\widetilde{q}_{-i}$. Therefore, from (4.2) it follows that given an implementation strategy $\sigma(q)$,

$$
h_{2}\left(q_{i} \mid \varphi, q_{-i}\right)=\frac{\operatorname{Pr}[\varphi \mid q] \sigma(q) g_{i}\left(q_{i}\right)}{\int \operatorname{Pr}[\varphi \mid \widehat{q}] \sigma(\widehat{q}) g_{i}\left(\widehat{q}_{i}\right) d \widehat{q}_{i}} .
$$

Suppose first that $\sigma(q)=\bar{\sigma}(q)$. Fix $q_{-i}$ such that $\bar{\sigma}(q)>0$ for some $q_{i}$. (This implies that given $q_{-i}$, $h_{2}(q \mid \varphi)>0$ for some $q_{i}$.) Because $\operatorname{Pr}[s \mid q]$ is strictly increasing in $q_{i}$ (recall that $\operatorname{Pr}[s \mid q]=\alpha_{A} q_{A}+\alpha_{B} q_{B}$ ) and $\bar{\sigma}(q)$ is non-decreasing in $q_{i}$ (recall that $\bar{\sigma}(q)=0$ if $q_{i} \leq \frac{z}{\alpha_{i}}+\frac{\alpha_{-i}}{\alpha_{i}} q_{-i}$ and $\bar{\sigma}(q)=1$ if otherwise), $H_{2}\left(q_{i} \mid s, q_{-i}\right)$ first-order stochastically dominates $G_{i}\left(q_{i}\right)$ and $H_{2}\left(q_{i} \mid s, q_{-i}\right)<G_{i}\left(q_{i}\right)$ on some open subset of $[0,1]$. This implies that $\mathbb{E}\left[\widetilde{q}_{i} \mid s, q_{-i}\right]>r_{i}$.

Suppose now that $\sigma(q)=\underline{\sigma}(q)$. Fix $q_{-i}$ such that $\underline{\sigma}(q)>0$ for some $q_{i}$. Because $\operatorname{Pr}[f \mid q]$ is strictly decreasing in $q_{i}\left(\right.$ recall that $\left.\operatorname{Pr}[f \mid q]=1-\alpha_{A} q_{A}-\alpha_{B} q_{B}\right)$ and $\underline{\sigma}(q)$ is non-increasing in $q_{i}$ (recall that $\underline{\sigma}(q)=1$ 
if $q_{i}<\frac{z}{\alpha_{i}}+\frac{\alpha_{-i}}{\alpha_{i}} q_{-i}$ and $\underline{\sigma}(q)=0$ if otherwise), $G_{i}\left(q_{i}\right)$ first-order stochastically dominates $H_{2}\left(q_{i} \mid f, q_{-i}\right)$ and $G_{i}\left(q_{i}\right)<H_{2}\left(q_{i} \mid f, q_{-i}\right)$ on some open subset of $[0,1]$. This implies that $\mathbb{E}\left[\widetilde{q}_{i} \mid f, q_{-i}\right]<r_{i}$, which concludes the proof.

Proof of Lemma 1. By definition,

$$
r_{i}^{\prime \prime}(\varphi)=\int q_{i} d H_{2}(q \mid \varphi)
$$

Because $H_{2}(q \mid \varphi)$ is obtained through Bayes rule from $H_{1}(q)$, it follows that

$$
h_{2}(q \mid \varphi)=\frac{\operatorname{Pr}[\varphi \mid q] h_{1}(q)}{\int \operatorname{Pr}[\varphi \mid \widehat{q}] d H_{1}(\widehat{q})} .
$$

Applying this result in (6.3) and using standard integration properties, we can write

$$
r_{i}^{\prime \prime}(\varphi)=\frac{\int q_{i} \operatorname{Pr}[\varphi \mid q] d H_{1}(q)}{\int \operatorname{Pr}[\varphi \mid \widehat{q}] d H_{1}(\widehat{q})} .
$$

From (6.4) and the fact that $\operatorname{Pr}[s \mid q]=\alpha_{A} q_{A}+\alpha_{B} q_{B}$ and $\operatorname{Pr}[f \mid q]=1-\alpha_{A} q_{A}-\alpha_{B} q_{B}$, it follows that

$$
r_{i}^{\prime \prime}(s)=\frac{\alpha_{i} \mathbb{E}\left[\widetilde{q}_{i}^{2}\right]+\left(1-\alpha_{i}\right) \mathbb{E}\left[\widetilde{q}_{A} \widetilde{q}_{B}\right]}{\alpha_{A} r_{A}^{\prime}+\alpha_{B} r_{B}^{\prime}}
$$

and

$$
r_{A}^{\prime \prime}(f)=\frac{r_{i}^{\prime}-\alpha_{i} \mathbb{E}\left[\widetilde{q}_{i}^{2}\right]+\left(1-\alpha_{i}\right) \mathbb{E}\left[\widetilde{q}_{A} \widetilde{q}_{B}\right]}{1-\alpha_{A} r_{A}^{\prime}-\alpha_{B} r_{B}^{\prime}},
$$

where $\mathbb{E}\left[\widetilde{q}_{i}^{2}\right]$ and $\mathbb{E}\left[\widetilde{q}_{A} \widetilde{q}_{B}\right]$ are expected values according to interim beliefs $H_{1}(q)$.

The results in the Lemma follow by subtracting $r_{i}^{\prime}$ from both sides of (6.5) and (6.6), and using the fact that $\operatorname{var}(\widetilde{y})=\mathbb{E}\left(\widetilde{y}^{2}\right)-\mathbb{E}^{2}(\widetilde{y})$ and $\operatorname{cov}\left(\widetilde{y}_{1}, \widetilde{y}_{2}\right)=\mathbb{E}\left(\widetilde{y}_{1} \widetilde{y}_{2}\right)-\mathbb{E}\left(\widetilde{y}_{1}\right) E\left(\widetilde{y}_{2}\right)$ for any given random variables $\widetilde{y}, \widetilde{y}_{1}$, and $\widetilde{y}_{2}$.

Proof of Lemma 2. We begin by introducing some additional notation. Let $\Pi_{j}(q)$ denote firms' joint profit under individual implementation of the joint project by firm $j \in\{\mathrm{A}, \mathrm{B}\}$. Moreover, let $\widehat{r}_{A}(\varphi)$ denote firm A's reputation if firm A implements the joint project alone and the performance of the joint project is $\varphi \in$ $\{f, s\}$. First, note that $\Pi_{B}(q)=r_{B} V+r_{A} V_{A} \geq r_{A} V_{A}=\Pi_{0}(q)$, which implies that individual implementation of the joint project by firm $B$ always dominates no implementation of the joint project. Thus, the best alternative to a partnership is either individual implementation by firm A or individual implementation by firm B. We now compare these two alternatives. Note that $\Pi_{A}(q)=r_{A} V+\left\{q_{A} \widehat{r}_{A}(s)+\left(1-q_{A}\right) \widehat{r}_{A}(f)\right\} V_{A}$. Applying Lemma 1 when $\alpha_{A}=1$ and noting that when firm A implements the joint project alone consumers' interim beliefs are identical to their initial beliefs, we obtain that $\widehat{r}_{A}(s)=r_{A}+\left(1 / r_{A}\right) \times \operatorname{var}\left(\widetilde{q}_{A}\right)$ and 
$\widehat{r}_{A}(f)=r_{A}-\left(1 /\left(1-r_{A}\right)\right) \times \operatorname{var}\left(\widetilde{q}_{A}\right)$. Using this and the fact that $\widehat{r}_{A}(s)>\widehat{r}_{A}(f)$, we immediately obtain that $\Pi_{A}(q) \geq \Pi_{B}(q)$ is equivalent to (5.1).

Proof of Proposition 1. In a pooling equilibrium with full implementation, consumers' interim beliefs about firms' qualities are identical to their initial beliefs — note from (4.1) that $h_{1}(q)=g(q)$ for all $q \in[0,1]^{2}$, when $\sigma(q)=1$ for all $q \in[0,1]^{2}$. This has two implications. First, $r_{i}^{\prime}=r_{i}$ for all $i \in\{\mathrm{A}, \mathrm{B}\}$. Second, $\operatorname{cov}\left(\widetilde{q}_{A}, \widetilde{q}_{B}\right)$ according to interim beliefs is 0 , since firms' qualities are initially perceived as independent. Because $\operatorname{cov}\left(\widetilde{q}_{A}, \widetilde{q}_{B}\right)$ according to interim beliefs is 0 , Lemma 1 implies that $r_{i}^{\prime \prime}(s)-r_{i}^{\prime \prime}(f)>0$ for all $i \in\{\mathrm{A}, \mathrm{B}\}$. Thus, firms' joint profit associated with implementing the joint project is increasing in both $q_{A}$ and $q_{B}$. This, together with the fact that firms' joint profit associated with not implementing the joint project does not depend on firms' qualities, implies that a pooling equilibrium with full implementation exists if and only if firms with qualities $q=(0,0)$ are better off forming the partnership than not forming it, i.e., $\Pi_{P}(0,0)>r_{A} V_{A}+r_{B} V_{B}$. Using the fact that $r_{i}^{\prime}=r_{i}$ for all $i \in\{\mathrm{A}, \mathrm{B}\}$ and Lemma 1 to substitute for $r_{i}^{\prime \prime}(f)$, we immediately obtain that this condition holds if and only if $V>V^{*}$.

Proof of Proposition 2. We first show that a higher quality partners equilibrium always exists when $V<V^{*}$. Let $\sigma_{z}(q)$ denote the following implementation strategy: $\sigma_{z}(q)=1$ if $q \in\left\{\left(q_{A}, q_{B}\right) \in[0,1]^{2}\right.$ : $\left.\alpha_{A} q_{A}+\alpha_{B} q_{B}>z\right\}$ and $\sigma_{z}(q)=0$ if otherwise. Let $r_{i, z}^{\prime}$ for $i \in\{\mathrm{A}, \mathrm{B}\}$ denote the interim reputations of firms A and B implied by the implementation strategy $\sigma_{z}(q)$, i.e., the reputations obtained from the interim posterior (4.1) when $\sigma(q)=\sigma_{z}(q)$. In a similar way, let $r_{i, z}^{\prime \prime}(s)$ and $r_{i, z}^{\prime \prime}(f)$ for $i \in\{\mathrm{A}, \mathrm{B}\}$ denote the ex-post reputations of firms $\mathrm{A}$ and $\mathrm{B}$ implied by the implementation strategy $\sigma_{z}(q)$, i.e., the reputations obtained from the ex-post posterior (4.2) when $\sigma(q)=\sigma_{z}(q)$. Given these reputations, firms' expected joint profit if they implement the joint project is greater than their joint profit if they do not implement it iff

$$
\alpha_{A} q_{A}+\alpha_{B} q_{B}>\frac{\sum_{i=A, B}\left[r_{i}-r_{i, z}^{\prime \prime}(f)\right] V_{i}-\left[\alpha_{A} r_{A, z}^{\prime}+\alpha_{B} r_{B, z}^{\prime}\right] V}{\sum_{i=A, B}\left[r_{i, z}^{\prime \prime}(s)-r_{i, z}^{\prime \prime}(f)\right] V_{i}} \equiv n(z),
$$

as long as

$$
\sum_{i=A, B}\left[r_{i, z}^{\prime \prime}(s)-r_{i, z}^{\prime \prime}(f)\right] V_{i}>0
$$

We establish existence of a higher quality partners equilibrium (when $V<V^{*}$ ) by showing that there exists $z^{*} \in[0,1)$ such that $(6.8)$ holds when $z=z^{*}$ and $n\left(z^{*}\right)=z^{*}$.

When $z=0, r_{i, z}^{\prime \prime}(s)$ and $r_{i, z}^{\prime \prime}(f)$ for all $i \in\{\mathrm{A}, \mathrm{B}\}$ are the same as in an equilibrium in which firms implement the joint project independently of their qualities, since only firms with qualities $q=(0,0)$ do not implement the joint project and these are of measure zero because $g(q)$ is atomless. This implies that $r_{i, z=0}^{\prime \prime}(s)>r_{i, z=0}^{\prime \prime}(f)$ for all $i \in\{\mathrm{A}, \mathrm{B}\}$, which in turn implies that the denominator of $n(0)$ is positive. For $V=V^{*}$ the numerator of $n(0)$ is zero. Thus, $n(0) \geq 0$ when $V \leq V^{*}$. 
Consider now the smallest $z$ such that $\sum_{i=A, B}\left[r_{i}-r_{i, z}^{\prime \prime}(f)\right] V_{i}=0$. Denote it by $z^{\prime}$. Note that $z^{\prime}$ exists and $z^{\prime} \in(0,1)$, since, for $i \in\{\mathrm{A}, \mathrm{B}\}, r_{i}>r_{i, z=0}^{\prime \prime}(f), \lim _{z \rightarrow 1} r_{i, z}^{\prime \prime}(f)=1$, and $r_{i, z}^{\prime \prime}(f)$ is a continuous function of $z$. From Lemma 3 (see Appendix A.2), $r_{i, z}^{\prime \prime}(s)>r_{i}$ for all $z \in[0,1)$. Therefore, for all $z \in\left[0, z^{\prime}\right]$ the denominator of $n(z)$ is positive. This implies two things. First, it implies that $n(z)$ is continuous for $z \in\left[0, z^{\prime}\right]$. (Note that $r_{i, z}^{\prime}, r_{i, z}^{\prime \prime}(s)$ and $r_{i, z}^{\prime \prime}(f)$ are all continuous functions of $z$ for all $i \in\{\mathrm{A}, \mathrm{B}\}$.) Second, it implies that $n\left(z^{\prime}\right)<0$, since the second term in the numerator of $n(z)$ is always positive and, by definition of $z^{\prime}$, the first term in the numerator of $n(z)$ is zero. Now, if $n(0)=0$ then let $z^{*}=0$. If $n(0)>0$, then existence of $z^{*} \in\left(0, z^{\prime}\right)$ is guaranteed by continuity of $n(z)$ for $z \in\left[0, z^{\prime}\right]$ and by the fact that $n\left(z^{\prime}\right)<0$.

We now prove the second part of the Proposition. For an example where a lower quality partners equilibrium exists, and its characterization, see Example 3 in Appendix A.1. For examples of situations where a lower quality partners equilibrium does not exist note that we have shown in the first part of Appendix A.2 that a lower quality partners equilibrium can exist only if $V>0$, and that a lower quality partners equilibrium in which the reputation of firm $i \in\{\mathrm{A}, \mathrm{B}\}$ decreases following a success of the joint project can exist only if $\alpha_{i}<V_{i} /\left(V_{A}+V_{B}\right)$.

Proof of Proposition 3. We start by showing point (i) of the Proposition. This is equivalent to showing that $r_{i}^{\prime} \geq r_{i}$ in any higher quality partners equilibrium for all $i \in\{\mathrm{A}, \mathrm{B}\}$. Let $\mathbb{E}\left[\widetilde{q}_{i}\right]$ be the expected value of $\widetilde{q}_{i}$ according to the interim distribution $H_{1}(q)$. By definition $r_{i}^{\prime}=\mathbb{E}\left[\widetilde{q}_{i}\right]$. By the law of iterated expectations we can write $r_{i}^{\prime}=\mathbb{E}_{q_{-i}}\left\{\mathbb{E}\left[\widetilde{q}_{i} \mid q_{-i}\right]\right\}$. Thus, a sufficient condition for point $(i)$ of the Proposition to hold is that in any higher quality partners equilibrium, $\mathbb{E}\left[\widetilde{q}_{i} \mid q_{-i}\right] \geq r_{i}$ for all $q_{-i}$ such that $h_{1}(q)>0$ for some $q_{i}$. The $\mathbb{E}\left[\widetilde{q}_{i} \mid q_{-i}\right]$ is the expected value of $\widetilde{q}_{i}$ according to the interim conditional distribution of $\widetilde{q}_{i}$ given $q_{-i}$. Denote the density associated with this conditional distribution by $h_{1}\left(q_{i} \mid q_{-i}\right)$. By the law of conditional probabilities

$$
h_{1}\left(q_{i} \mid q_{-i}\right)=\frac{h_{1}(q)}{h_{1,-i}\left(q_{-i}\right)},
$$

where $h_{1,-i}\left(q_{-i}\right)=\int h_{1}(q) d q_{i}$. Consider an equilibrium where firms' implementation strategy is $\sigma(q)$. From (6.9) and (4.1), it follows that in this equilibrium

$$
h_{1}\left(q_{i} \mid q_{-i}\right)=\frac{\sigma(q) g_{i}\left(q_{i}\right)}{\int \sigma(\widehat{q}) g_{i}\left(\widehat{q}_{i}\right) d \widehat{q}_{i}} .
$$

Fix $q_{-i}$ such that $\sigma(q)>0$ for some $q_{i}$. (This implies that given $q_{-i}, h_{1}(q)>0$ for some $q_{i}$.) Because $\sigma(q)$ is non-decreasing in $q_{i}$ in a higher quality partners equilibrium (recall that in this type of equilibrium $\sigma(q)=0$ if $q_{i} \leq \frac{z}{\alpha_{i}}+\frac{\alpha_{-i}}{\alpha_{i}} q_{-i}$ and $\sigma(q)=1$ if otherwise), $H_{1}\left(q_{i} \mid q_{-i}\right)$ first-order stochastically dominates $G_{i}\left(q_{i}\right)$, which implies that $\mathbb{E}\left[\widetilde{q}_{i} \mid q_{-i}\right] \geq r_{i}$. This completes the proof that $r_{i}^{\prime} \geq r_{i}$ in a higher quality partners equilibrium for all $i \in\{\mathrm{A}, \mathrm{B}\}$. 
To prove point $(i i)$ of the Proposition, we provide here an example where firms' types are continuous inspired by Example 1, a two-type firms example. Suppose that $g_{i}\left(q_{i}\right)=d$ if $q_{A} \in[d, 1-d]$ and $g_{i}\left(q_{i}\right)=$ $\left(2 d^{2}-d+1\right) / 2 d$ if otherwise, for all $i \in\{\mathrm{A}, \mathrm{B}\}$. Note that when $d$ goes to 0 , this distribution collapses in the distribution in Example 1. Let $d=0.1, \alpha_{A}=1 / 4$ (which implies $\alpha_{B}=3 / 4$ ), $V=0.5, V_{A}=2$, and $V_{B}=5$. Let also $n(z), r_{i, z}^{\prime \prime}(\varphi)$ and $r_{i, z}^{\prime}$ for all $i \in\{\mathrm{A}, \mathrm{B}\}$ and for all $\varphi \in\{f, s\}$ be as defined in the Proof of Proposition 2. In this case: $(a) n(0.1)=0.10094$ and $n(0.225)=-0.014450 ;(b) \sum_{i=A, B}\left[r_{i, z}^{\prime \prime}(s)-r_{i, z}^{\prime \prime}(f)\right] V_{i}>0$ for all $z \in[0.1,0.225]$, which implies that $n(z)$ is continuous in $[0.1,0.225]$; and $(c) r_{A, z}^{\prime \prime}(s)<r_{A, z}^{\prime}<r_{A, z}^{\prime \prime}(f)$ for all $z \in[0.1,0.225]$. It follows from $(a)$ and $(b)$ that there exists an equilibrium where firms implement the joint project iff $\alpha_{A} q_{A}+\alpha_{B} q_{B}>z^{*}$ from some $z^{*} \in(0.1,0.225)$, and from $(c)$ that in such an equilibrium the reputation of firm A increases (resp. decreases) following a failure (resp. success) of the joint project.

Point (iii) of the Proposition, which is equivalent to the statement that in a higher quality partners equilibrium $r_{i}^{\prime \prime}(s)>r_{i}$ for all $i \in\{\mathrm{A}, \mathrm{B}\}$, follows directly from Lemma 3 in Appendix A.2.

Proof of Proposition 4. Suppose that $V=V_{B}=0$. Let $g_{B}^{1}$ and $g_{B}^{2}$ denote two possible prior distributions of firm B's quality. Given prior $g_{A}$ of firm A's quality and firms' contributions $\alpha_{A}$ and $\alpha_{B}$, let $r_{A, z, j}^{\prime \prime}(f)$ and $r_{A, z, j}^{\prime \prime}(s)$ denote the ex-post reputations of firm A that are implied by the implementation strategy $\sigma_{z}(q)=1$ if $q \in\left\{\left(q_{A}, q_{B}\right) \in[0,1]^{2}: \alpha_{A} q_{A}+\alpha_{B} q_{B}>z\right\}$ and $\sigma_{z}(q)=0$ if otherwise, when the prior distribution of firm B's quality is $g_{B}^{j}$, for all $j \in\{1,2\}$. Furthermore, let $z_{j}^{*}$ denote the lowest combined quality threshold level above which firms implement the joint project in a higher quality partners equilibrium when the prior distribution of firm B's quality is $g_{B}^{j}$, for all $j \in\{1,2\}$. Note that a higher quality partners equilibrium exists, since $V=0$ (see Proposition 2).

The fact that $z_{j}^{*}$ is the combined quality threshold above which firms' implement the joint project in a higher quality partners equilibrium implies, by definition of equilibrium, that $n^{j}\left(z_{j}^{*}\right)=z_{j}^{*}$, where

$$
n_{j}(z) \equiv \frac{\left[r_{A}-r_{A, z, j}^{\prime \prime}(f)\right]}{\left[r_{A, z, j}^{\prime \prime}(s)-r_{A, z, j}^{\prime \prime}(f)\right]} .
$$

Furthermore, the fact that $z_{j}^{*}$ corresponds to the lowest of such combined quality threshold levels when the prior distribution of firm B's quality is $g_{B}^{j}$ implies, for all $j \in\{1,2\}$, that both the numerator and the denominator of $n_{j}(z)$ are positive for all $z \in\left[0, z_{j}^{*}\right]$ (see the proof of Proposition 2 in Appendix A.2.). We continue the proof by focusing on the case: $\alpha_{A}=\alpha_{B}=1 / 2, g_{A}\left(q_{A}\right)=1$ for all $q_{A} \in[0,1], g_{B}^{1}\left(q_{B}\right)=1$ for all $q_{B} \in[0,1]$, and $g_{B}^{2}\left(q_{B}\right)=2 q_{B}$ for all $q_{B} \in[0,1]$. Note that firm B's initial reputation under the prior $g_{B}^{1}$ is $1 / 2$. This is smaller than firm B's reputation under the prior $g_{B}^{2}$, which is $2 / 3$. Moreover, using (4.2) we obtain in this case that: $r_{A, z, 1}^{\prime \prime}(s)=\left(7-24 z^{4}\right) /\left(12-32 z^{3}\right)$ if $z \leq 1 / 2$ and $r_{A, z, 1}^{\prime \prime}(s)=\left(2 z+3 z^{2}+1\right) /(4 z+2)$ if $z>1 / 2$; $r_{A, z, 1}^{\prime \prime}(f)=\left(24 z^{4}-32 z^{3}+5\right) /\left(32 z^{3}-48 z^{2}+9\right)$ if $z \leq 1 / 2$ and $r_{A, z, 1}^{\prime \prime}(f)=(3 z+1) / 4$ if $z>1 / 2 ; r_{A, z, 2}^{\prime \prime}(s)=$ $\left(64 z^{5}-20\right) /\left(120 z^{4}-35\right)$ if $z \leq 1 / 2$ and $r_{A, z, 2}^{\prime \prime}(s)=\left(4 z+16 z^{2}+8 z^{3}+2\right) /\left(10 z+15 z^{2}+5\right)$ if $z>1 / 2$; $r_{A, z, 2}^{\prime \prime}(f)=\left(64 z^{5}-80 z^{4}+10\right) /\left(120 z^{4}-160 z^{3}+25\right)$ if $z \leq 1 / 2$ and $r_{A, z, 2}^{\prime \prime}(f)=\left(14 z+8 z^{2}-2\right) /(15 z+5)$ 
if $z>1 / 2$. It follows that $r_{A, z, 2}^{\prime \prime}(f)<r_{A, z, 1}^{\prime \prime}(f)$ and $r_{A, z, 2}^{\prime \prime}(s)<r_{A, z, 1}^{\prime \prime}(s)$ for all $z \in[0,1)$. This implies that $n_{2}(z)>n_{1}(z)$ for all $z$ such that both the numerator and the denominator of $n_{2}(z)$ and $n_{1}(z)$ are positive. Thus, $n_{2}(z)>n_{1}(z)$ for all $z \in\left[0, \min \left\{z_{1}^{*}, z_{2}^{*}\right\}\right]$. This implies that $z_{1}^{*}<z_{2}^{*}$, since $z_{j}^{*}$ must satisfy $n_{j}\left(z_{j}^{*}\right)=z_{j}^{*}$, for all $j \in\{1,2\}$. This establishes the result in the Proposition. The case in which we focus here is a special case of a more general result. In fact, it can be shown that if distributions $g_{B}^{1}$ and $g_{B}^{2}$ satisfy the monotone likelihood ratio property in the sense that $g_{B}^{2}\left(q_{B}\right) / g_{B}^{1}\left(q_{B}\right)$ is increasing in $q_{B}$ in the interval $[0,1]$, $r_{A, z, 2}^{\prime \prime}(f) \leq r_{A, z, 1}^{\prime \prime}(f)$ and $r_{A, z, 2}^{\prime \prime}(s) \leq r_{A, z, 1}^{\prime \prime}(s)$ for all $z \in[0,1)$, implying that $z_{1}^{*} \leq z_{2}^{*}$ when $V=V_{B}=0$.

Proof of Proposition 5. Suppose that an equilibrium where firms form a partnership regardless of their qualities exists. In such an equilibrium, the decision to form a partnership is uninformative to consumers about firms' qualities. This implies that $r_{i}^{\prime}=r_{i}$, for all $i \in\{\mathrm{A}, \mathrm{B}\}$. Consider first the case of firms with qualities $q=(0,0)$ in this equilibrium. Firms' joint profit if they form a partnership, which is equal to $\left(\alpha_{A} r_{A}+\alpha_{B} r_{B}\right) V+r_{A}^{\prime \prime}(f) V_{A}$, must be greater than their joint profit if firm B implements the project alone, which is equal to $r_{B} V+r_{A} V_{A}$. Using the fact that $\alpha_{A}+\alpha_{B}=1$, this condition is equivalent to

$$
\alpha_{A}\left[r_{A}-r_{B}\right] V>V_{A}\left[r_{A}-r_{A}^{\prime \prime}(f)\right]
$$

From Lemma 1 and the fact that in this type of equilibrium interim beliefs in case a partnership is formed are identical to initial beliefs, it follows that $r_{A}>r_{A}^{\prime \prime}(f)$. This implies that the right-hand side of (6.10) is (strictly) positive, which implies that

$$
\left[r_{A}-r_{B}\right] V>0
$$

Consider now the case of firms with qualities $q=(1,0)$ in the equilibrium under consideration here. Let $\widehat{r}_{A}(\varphi)$ denote firm A's reputation if firm A implements the joint project alone and the performance of the joint project is $\varphi \in\{f, s\}$. Firms' joint profit if they form a partnership, which is equal to

$$
\left[\alpha_{A} r_{A}+\alpha_{B} r_{B}\right] V+\left\{\alpha_{A}\left[r_{A}^{\prime \prime}(s)-r_{A}^{\prime \prime}(f)\right]+r_{A}^{\prime \prime}(f)\right\} V_{A},
$$

must be greater than their joint profit if firm A implements the project alone, which is equal to $r_{A} V+\widehat{r}_{A}(s) V_{A}$. This condition is equivalent to

$$
\left(1-\alpha_{A}\right) V\left[r_{B}-r_{A}\right]>V_{A}\left\{\widehat{r}_{A}(s)-r_{A}^{\prime \prime}(f)-\alpha_{A} \Delta r_{A}^{\prime \prime}\right\}
$$

where $\Delta r_{A}^{\prime \prime}=r_{A}^{\prime \prime}(s)-r_{A}^{\prime \prime}(f)$. Since $\alpha_{A}<1$ and $\Delta r_{A}^{\prime \prime}>0$ (use Lemma 1 and the fact that in this type of equilibrium $\left.H_{1}(q)=G(q)\right)$, (6.12) implies that

$$
\left(1-\alpha_{A}\right) V\left[r_{B}-r_{A}\right] \geq V_{A}\left[\widehat{r}_{A}(s)-r_{A}^{\prime \prime}(f)-\Delta r_{A}^{\prime \prime}\right],
$$

which is equivalent to

$$
\left(1-\alpha_{A}\right) V\left[r_{B}-r_{A}\right] \geq V_{A}\left[\widehat{r}_{A}(s)-r_{A}^{\prime \prime}(s)\right]
$$


By Lemma 1,

$$
\widehat{r}_{A}(s)-r_{A}^{\prime \prime}(s)=\operatorname{var}\left(\widetilde{q}_{A}\right) \frac{\alpha_{B} r_{B}}{r_{A}\left(\alpha_{A} r_{A}+\alpha_{B} r_{B}\right)}>0,
$$

where $\operatorname{var}\left(\widetilde{q}_{A}\right)$ is the variance of $\widetilde{q}_{A}$ according to $G_{A}(q)$. Thus, the right-hand side of (6.13) is (strictly) positive, which implies that

$$
\left[r_{B}-r_{A}\right] V>0
$$

Clearly, conditions (6.11) and (6.14) cannot hold simultaneously. This completes the proof.

Proof of Proposition 6. Consider a higher quality partners equilibrium. Firms' expected joint profit if they form a partnership and implement the joint project is given by

$$
\Pi_{P}(q)=\left[\alpha_{A} r_{A}^{\prime}+\alpha_{B} r_{B}^{\prime}\right] V+\left\{\left(\alpha_{A} q_{A}+\alpha_{B} q_{B}\right)\left[r_{A}^{\prime \prime}(s)-r_{A}^{\prime \prime}(f)\right]+r_{A}^{\prime \prime}(f)\right\} V_{A}
$$

Let $\Pi_{A}(q)$ denote firms' joint profit if firm A implements the joint project alone and $\Pi_{B}(q)$ denote firms' joint profit if firm B does it. If $q_{A}<q_{A}^{*}$, by Lemma 2 the best alternative to a partnership is individual implementation by firm B. Thus, firms form a partnership if and only if

$$
\Pi_{P}(q)>\Pi_{B}(q)
$$

Since $\Pi_{B}(q)=r_{B} V+r_{A} V_{A}$ and by definition in a higher quality partners equilibrium $r_{A}^{\prime \prime}(s)>r_{A}^{\prime \prime}(f)$, we obtain that $(6.16)$ is equivalent to

$$
\alpha_{A} q_{A}+\alpha_{B} q_{B}>z,
$$

where

$$
z=\frac{\left[r_{A}-r_{A}^{\prime \prime}(f)\right] V_{A}+\left[r_{B}-\alpha_{A} r_{A}^{\prime}-\alpha_{B} r_{B}^{\prime}\right] V}{\left[r_{A}^{\prime \prime}(s)-r_{A}^{\prime \prime}(f)\right] V_{A}} .
$$

Thus, firms form a partnership if their combined quality is above the threshold $z$. If $q_{A}>q_{A}^{*}$, the best alternative to a partnership is individual implementation by firm A. Thus, firms form a partnership if and only if

$$
\Pi_{P}(q)>\Pi_{A}(q)
$$

Let $\widehat{r}_{A}(\varphi)$ denote firm A's reputation if firm A implements the joint project alone and the performance of the joint project is $\varphi \in\{f, s\}$. Since $\Pi_{A}(q)=r_{A} V+\left\{q_{A} \widehat{r}_{A}(s)+\left(1-q_{A}\right) \widehat{r}_{A}(f)\right\} V_{A}$ and in a higher quality partners equilibrium $r_{A}^{\prime \prime}(s)>r_{A}^{\prime \prime}(f)$, we obtain that (6.19) is equivalent to

$$
q_{B}-\psi q_{A}>\psi_{0}
$$

where

$$
\psi_{0}=\frac{\left[\widehat{r}_{A}(f)-r_{A}^{\prime \prime}(f)\right] V_{A}+\left[r_{A}-\alpha_{A} r_{A}^{\prime}-\alpha_{B} r_{B}^{\prime} V\right]}{\left(1-\alpha_{A}\right)\left[r_{A}^{\prime \prime}(s)-r_{A}^{\prime \prime}(f)\right]}
$$


and

$$
\psi=\frac{\left[\widehat{r}_{A}(s)-\widehat{r}_{A}(f)\right]-\alpha_{A}\left[r_{A}^{\prime \prime}(s)-r_{A}^{\prime \prime}(f)\right]}{\left(1-\alpha_{A}\right)\left[r_{A}^{\prime \prime}(s)-r_{A}^{\prime \prime}(f)\right]} .
$$

Moreover, from the fact that $\Pi_{B}(q)=\Pi_{A}(q)$ when $q_{A}=q_{A}^{*}$ and that $\Pi_{P}(q)$ is continuous in $q_{A}$, it follows that conditions (6.17) and (6.20) must be identical when $q_{A}=q_{A}^{*}$. This implies that $\psi_{0}=z /\left(1-\alpha_{A}\right)-$ $\left(\alpha_{A} /\left(1-\alpha_{A}\right)+\psi\right) q_{A}^{*}$. The result in the Proposition for $q_{A}>q_{A}^{*}$ follows directly from the fact that $\psi>$ $-\alpha_{A} / \alpha_{B}=-\alpha_{A} /\left(1-\alpha_{A}\right)$. To see that $\psi>-\alpha_{A} /\left(1-\alpha_{A}\right)$, note that $r_{A}^{\prime \prime}(s)-r_{A}^{\prime \prime}(f)>0$ and that by applying Lemma 1 when $\alpha_{A}=1$ we obtain $\widehat{r}_{A}(s)-\widehat{r}_{A}(f)>0$. This completes the proof. 


\section{References}

[1] ALSOP, R. (2004). "Corporate Reputation: Anything but Superficial-The Deep but Fragile Nature of Corporate Reputation", Journal of Business Strategy, 25(6), 21-29.

[2] ARROW, K. (1974). The Limits of Organization, W. W. Northon \& Company, New York.

[3] ANDERSON, A. and L. SMITH (2006). "Assortative Matching and Reputation", Cowles Foundation discussion paper No. 1553.

[4] BAR-ISAAC, H. (forthcoming). "Something to Prove: Reputation in Teams", Rand Journal of Economics.

[5] CABRAL, L. (2000). "Stretching Firm and Brand Reputation", Rand Journal of Economics, 31(4), 658-673.

[6] ENGERS, M. (1987). "Signalling with Many Signals", Econometrica, 55(3), 663-674.

[7] GERINGER, J. M. (1988). Joint Venture Partner Selection: Strategies for Developed Countries, Quorum Books, Westport, CT.

[8] HAKENES, H. and M. PEITZ (2007). "Observable Reputation Trading", International Economic Review, 48(2), 693-730.

[9] HITT, M. A., M. T. DACIN, E. LEvitAS, J.-L. ARREGLE and A. BORZA. (2000). "Partner Selection in Emerging and Developed Market Contexts: Resource-Based and Organizational Learning Perspectives", Academy of Management Journal, 43(3), 449-467.

[10] HOLMSTRÖM, B. (1999). "Managerial Incentive Problems: a Dynamic Perspective", Review of Economic Studies, 66(1), 169-182.

[11] HÖRNER, J. (2002). "Reputation and Competition", American Economic Review, 92(3), 644-663.

[12] JEON, S. (1996). "Moral Hazard and Reputational Concerns in Teams: Implications for Organizational Choice", International Journal of Industrial Organization, 14, 297-315.

[13] KLEIN, B. and K. LEFFLER (1981). "The Role of Market Forces in Assuring Contractual Performance", Journal of Political Economy, 89, 615-641.

[14] KREPS, D. and R. WILSON (1982). "Reputation and Imperfect Information", Journal of Economic Theory, 27, 253-279. 
[15] LANG, G. (2003). "Reputation Deals: A Theory of Endogenous Teams", Atlantic Economic Journal, 31(1), 32-50.

[16] MAILATH, J. and L. SAMUELSON (2001). "Who Wants a Good Reputation?", Review of Economic Studies, 68(2), 415-441.

[17] MIKLÓS-THAL, J. (2008) "Linking Reputations: The Signaling and Feedback Effects of Umbrella Branding", mimeo, University of Mannheim.

[18] MiLGROM, P. and J. ROBERTS (1982). "Predation, Reputation and Entry Deterrence", Journal of Economic Theory, 27, 253-279.

[19] MORRISON, A. and W. WILHELM (2004). "Partnership Firms, Reputation, and Human Capital", American Economic Review, 94(5), 1682-1692.

[20] QUINZII, M. and J.-C. ROCHET (1985). "Multidimensional Signalling", Journal of Mathematical Economics, 14, 261-284.

[21] ROCHET, J.-C. and P. CHONE (1998). "Ironing, Sweeping, and Multidimensional Screening", Econometrica, 66(4), 783-826.

[22] SEGENDORFF, B. (2000). "A Signalling Theory of Scapegoats", Stockholm School of Economics working paper No. 406.

[23] SHAPIRO, C. (1983). "Premiums for High Quality Products as Returns to Reputation", Quarterly Journal of Economics, 98, 659-680.

[24] TADELIS, S. (1999). "What's in a Name? Reputation as a Tradeable Asset.", American Economic Review, 89, 548-563.

[25] TADELIS, S. (2002). "The Market for Reputations as an Incentive Mechanism", Journal of Political Economy, 110(4), 854-882.

[26] TIROLE, J. (1996). "A Theory of Collective Reputations (With Applications to the Persistence of Corruption and to Firm Quality)", The Review of Economic Studies, 63, 1-22.

[27] WERNERFELT, B. (1988). "Umbrella Branding as a Signal of New Product Quality: An Example of Signalling by Posting a Bond", Rand Journal of Economics , 19, 458-466.

[28] WILSON, R. (1985). "Multi-Dimensional Signalling", Economics Letters, 19, 17-21. 